OPEN ACCESS

Edited by:

Ning Zhang,

Stanford University, United States

Reviewed by

Neety Sahu,

Stanford University, United States

Xinming Tong,

Stanford University, United States

*Correspondence: Jianzhong Xu xujianzhong@zzu.edu.cn

Specialty section: This article was submitted to Integrative and Regenerative

Pharmacology,

a section of the journal

Frontiers in Pharmacology

Received: 08 August 2021 Accepted: 06 September 2021 Published: 16 September 2021

Citation:

Chen T, Weng W, Liu Y, Aspera-Werz RH, Nüssler AK and Xu J (2021) Update on Novel NonOperative Treatment for Osteoarthritis:

Current Status and Future Trends.

Front. Pharmacol. 12:755230.

doi: 10.3389/fphar.2021.755230

\section{Update on Novel Non-Operative Treatment for Osteoarthritis: Current Status and Future Trends}

\author{
Tao Chen ${ }^{1,2}$, Weidong Weng ${ }^{2}$, Yang Liu ${ }^{3}$, Romina H. Aspera-Werz ${ }^{2}$, Andreas K Nüssler ${ }^{2}$ and \\ Jianzhong $\mathrm{Xu}^{1 *}$
}

${ }^{1}$ Department of Orthopedic Surgery, The First Affiliated Hospital of Zhengzhou University, Zhengzhou, China, ${ }^{2}$ Department of Trauma and Reconstructive Surgery, BG Trauma Center Tübingen, Siegfried Weller Institute for Trauma Research, Eberhard Karls University Tübingen, Tübingen, Germany, ${ }^{3}$ Department of Clinical Sciences, Orthopedics, Faculty of Medicine, Lund University, Lund, Sweden

Osteoarthritis $(O A)$ is a leading cause of pain and disability which results in a reduced quality of life. Due to the avascular nature of cartilage, damaged cartilage has a finite capacity for healing or regeneration. To date, conservative management, including physical measures and pharmacological therapy are still the principal choices offered for OA patients. Joint arthroplasties or total replacement surgeries are served as the ultimate therapeutic option to rehabilitate the joint function of patients who withstand severe OA. However, these approaches are mainly to relieve the symptoms of OA, instead of decelerating or reversing the progress of cartilage damage. Disease-modifying osteoarthritis drugs (DMOADs) aiming to modify key structures within the OA joints are in development. Tissue engineering is a promising strategy for repairing cartilage, in which cells, genes, and biomaterials are encompassed. Here, we review the current status of preclinical investigations and clinical translations of tissue engineering in the non-operative treatment of OA. Furthermore, this review provides our perspective on the challenges and future directions of tissue engineering in cartilage regeneration.

Keywords: tissue engineering, osteoarthritis, scaffold, gene, cartilage regeneration, non-operative

\section{INTRODUCTION}

Osteoarthritis (OA) is a degenerative joint disease and a leading cause of pain and disability among adults (El-Tawil et al., 2016). Over the past decades, along with both an aging population and an increasing obese rate, the incidence and prevalence of OA have a constant growth (Collaborators, 2016). It is estimated to be $18 \%$ of females and $9.6 \%$ of males aged $\geq 60$ years have symptomatic OA all over the world (Hunter and Bierma-Zeinstra, 2019). The direct medical cost of OA accounts for $1-2.5 \%$ of the gross domestic product in high-income countries (March et al., 2014). Nowadays, treatments designed for $\mathrm{OA}$ are various. Generally, treatments applied for subjects with mild to moderate OA (Kellgren-Lawrence [K-L] grade 1-3) include education, exercise, weight control, analgesics, and intra-articular (IA) injection of corticosteroids (CSs) or hyaluronic acid (HA) (Ringdahl and Pandit, 2011). These treatments may benefit some patients by reducing pain and improving joint mobility, but none of them can prevent the progressive destruction of cartilage. In advanced disease (K-L grade 4), joint arthroplasty or total replacement surgery has been the ultimate therapeutic option, especially for patients who are unsatisfied with other treatments (Ronn et al., 2011). However, these surgeries are incursive and irreversible procedures and are often accompanied 


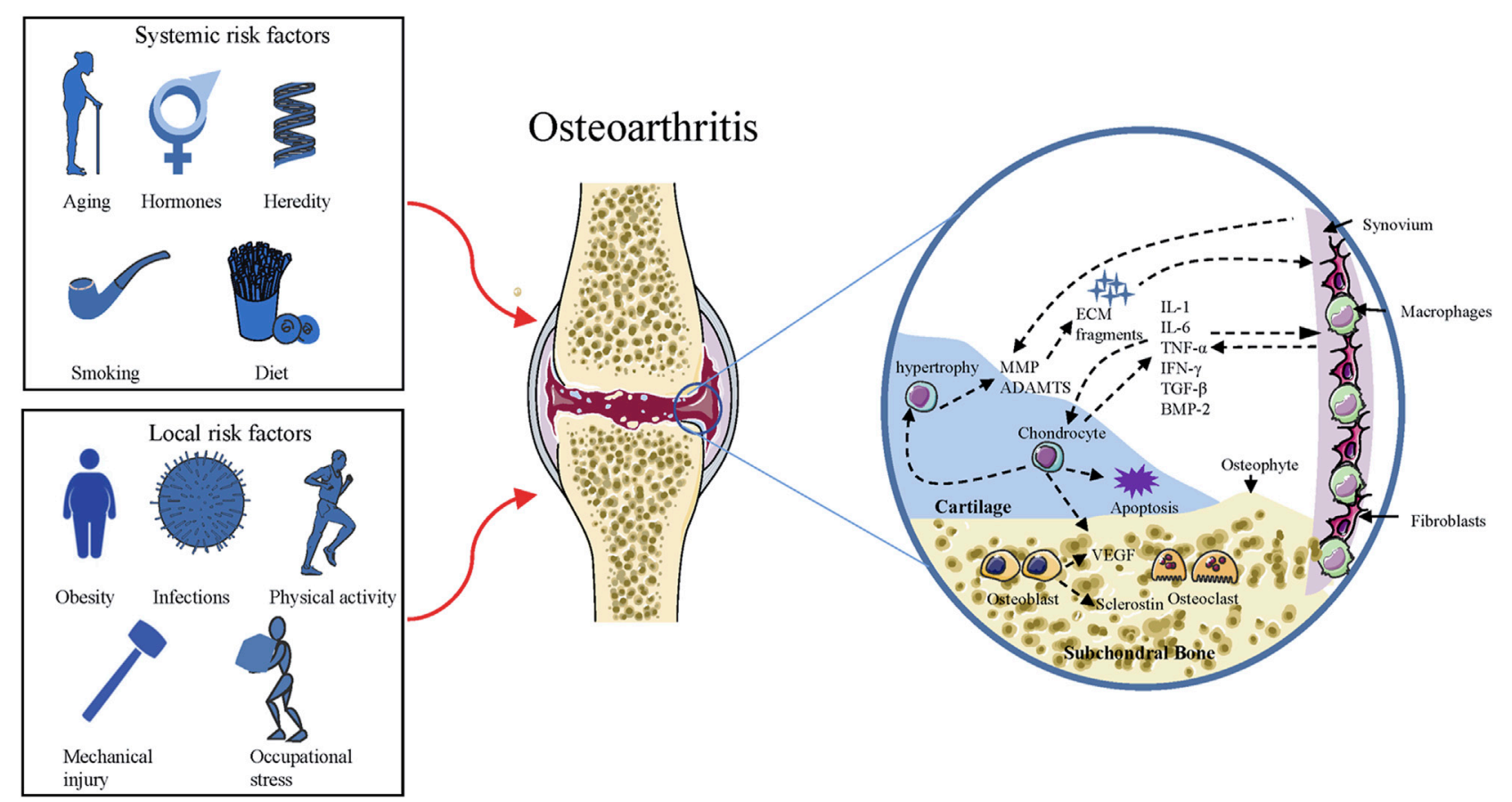

FIGURE 1 | Risk factors and pathogenic process of OA. Squares on the left side include the risk factors responsible for the development of OA, and the circle on the right side represents the pathogenic process of OA. ADAMTS = a disintegrin and metalloproteinase with thrombospondin motifs; MMP = matrix metalloproteinase; ECM = extracellular matrix; IL = interleukin; TNF = tumor necrosis factor; IFN = Interferon; BMP = bone morphogenic protein; TGF = transforming growth factor; VEGF = Vascular endothelial growth factor.

by serious complications (Ronn et al., 2011). In addition, many subjects who suffer from severe OA are relatively young, and they would undergo a second surgery to prevail a useful life. Therefore, the research and development of new therapeutic alternatives are urgent for OA.

On the other hand, OA has been increasingly recognized as a complex syndrome involving the whole joint tissues, while not defined as a single mechanical-induced disorder as before (Chen et al., 2017). Treatments for OA, therefore, have been shifted from the supportive to the preventive or regenerative, aiming at decelerating or reversing the progress of cartilage degeneration (Hunter and Bierma-Zeinstra, 2019). Many attempts have been made to therapeutic procedures for the early treatment of cartilage defects through non-operative approaches. A DMOAD is a drug that prevents the structural demolition of OA coupled with symptom relief (Oo et al., 2018). Some of the DMOADs are being assayed in clinical trials with advanced development (Ghouri and Conaghan, 2019).

In recent years, with the development of life sciences and biomaterials, tissue engineering has become a promising tool for cartilage regeneration (Liu Y. et al., 2017). Tissue engineering is thought a reparative treatment that mainly targets interference at the early stages of OA to maintain and restore the extracellular matrix (ECM) of cartilage (Liu Y. et al., 2017). It offers a possibility to regenerate cartilage by using cells, scaffolds, and genes alone or combined (Morouco et al., 2019).

In this review, we will provide an overview of current and potential non-surgical therapeutic alternatives for OA patients.
Representative strategies in preclinical animal models and clinical translations of humans using tissue engineering will be highlighted and discussed.

\section{CARTILAGE AND OA}

Human articular cartilage (AC) is a hyaline connective tissue designed to protect the diarthrodial joints. This highly specialized structure provides the joints with mechanical features, such as load-bearing, low friction, and smooth movement (Archer, 2003). It is comprised of sparsely distributed chondrocytes and a dense ECM, in which cells account for less than $5 \%$ of the total mass (Sophia Fox et al., 2009). The primary components of ECM are water, collagen, proteoglycan, and other matrix constituents. In healthy cartilage, water, collagen, and proteoglycan together make up $90-95 \%$ of total content, although their proportions vary across the cartilage (Akkiraju and Nohe, 2015).

$\mathrm{OA}$ is a disease with involvement of the whole joint, characterized by cartilage erosion, subchondral bone remodeling, synovial inflammation, osteophytes formation, as well as degeneration of ligaments and menisci (Chen et al., 2020). It is the most common arthritis associated with several risk factors (as indicated in Figure 1) in the pathogenesis of cartilage degeneration (Silverwood et al., 2015). The disease is an active variation that results from an imbalance between anabolic and catabolic activity, while not a passive degenerative disease or alleged "wear and tear" arthritis as described before (Chen et al., 
2017). Although much work has been conducted to understand how the balance is perturbed, it is still not clear-cut. During the process of $\mathrm{OA}$, changes that occur in cartilage are the alteration of cartilage composition and loss of cartilage integrity, which increases its susceptibility to disruption (Goldring and Goldring, 2007). Degenerative shifts in the cartilage lead to increased production of ECM fragments, which promote the release of pro-inflammatory cytokines, like interleukin-1 (IL-1), interleukin-6 (IL-6), and tumor necrosis factor- $\alpha$ (TNF- $\alpha$ ) (Scanzello and Goldring, 2012). Once secreted, these cytokines can modulate chondrocytes and adjacent synoviocytes metabolism, inducing the secretion of proteolytic enzymes, such as matrix metalloproteinases (MMPs) and a disintegrin and metalloproteinase with thrombospondin motifs (ADAMTS), which in turn aids in cartilage degradation and fragmentation (Fernandes et al., 2002; Chen et al., 2017). Elevated ECM fragments additionally stimulate the release of pro-inflammatory mediators and matrix degradation products, forming a vicious circle (Fernandes et al., 2002). Parallel to these changes in cartilage, proliferating synoviocytes also release pro-inflammatory and catabolic products, which adversely contribute to ECM degradation (Scanzello and Goldring, 2012). The deviant expression of growth factors, such as transforming growth factor $\beta$ (TGF- $\beta$ ), bone morphogenic protein 2 (BMP-2), and upregulated immune response, might bring about chondrocyte hypertrophy/apoptosis as well as osteophytes formation (Akkiraju and Nohe, 2015). In OA joints, subchondral bone undergoes remarkable remodeling processes in both composition and structure, including microarchitecture damage, bone marrow lesions, and bone cysts ( $\mathrm{Hu}$ et al., 2021). Subchondral bone remodeling is an adaptive change to local biomechanical and biological signals, which correspond to Wolff's Law (Zhu et al., 2020). When the bone is subjected to abnormal load-bearing, a number of bone properties change, including the increased bone mass, subchondral bone thickening, and trabecular restructuring (Zhu et al., 2020). These alterations are mediated by various types of cells, such as osteoblasts, osteoclasts, and osteocytes (Sims and Martin, 2020). Figure 1 summarizes the risk factors and pathogenic process of OA.

Disease severity does not correspond to the level of reported symptoms in OA patients. Some persons endure structural destructions in cartilage while they are asymptomatic (Hunter et al., 2008). Pain is the typical symptom presented in OA and a major driving force for seeking a clinical solution (Hunter et al., 2008). Pain, reduced movement, stiffness, joint instability, and swelling are essential symptoms in diagnosing OA (Hunter and Bierma-Zeinstra, 2019). Radiographic evidence of OA includes narrowing of joint space, subchondral bone thickening, and osteophytes formation (Braun and Gold, 2012).

\section{NON-OPERATIVE THERAPIES FOR OA}

\section{Non-Pharmacological and Pharmacological Treatments of $O A$}

At present, there is no cure for OA. Current non-surgical strategies for treating $\mathrm{OA}$ contain physical measures and pharmacological therapies. They are normally utilized for patients with mild or moderate OA (K-L grade 1-3) to relieve pain, increase joint motion and improve the quality of life (Ringdahl and Pandit, 2011).

\section{Non-Pharmacological Treatments of OA}

Nowadays, all guidelines agree that non-pharmacological treatments such as education and self-management, exercise, weight control, and walking aids should be central to the management of patients with OA (Zhang et al., 2010; Nelson et al., 2014). Most of the guidelines recommend strongly that OA patients should acquire up-to-date information and education to allow them to self-manage the disease to a certain extent (Zhang et al., 2008; Block, 2014). Exercise therapy (strengthening exercise and aerobic exercise) is helpful in reducing pain, improving joint motion, and strengthening muscles around the joints (Jordan et al., 2003). Obesity or overweight is associated with the prevalence and progression of knee OA, while weight loss can help to relieve their OA symptoms and delay the structural damage (Messier, 2009). The benefits of knee braces and other assistive devices for physical support and assistance are still controversial and not well-organized (Thomas et al., 2018). Besides, some alternative medicine treatments, like acupuncture, thermal modalities, and therapeutic ultrasound are likely to have little effect in reducing the pain of OA patients (Block, 2014).

\section{Pharmacological Treatments of OA}

Clinical evidence also suggests that some of OA patients will benefit from drugs (Ringdahl and Pandit, 2011). Drugs, including acetaminophen, non-steroidal anti-inflammatory drugs (NSAIDs), and opioids are essential medicine for patients who have moderate to severe pain. Among these drugs, acetaminophen and NSAIDs are recommended as the first-line pain medication for OA by most guidelines (Dougados, 2006; Hunter and Bierma-Zeinstra, 2019). Nonetheless, safety should be an important consideration in selecting these drugs, since they are reported to be related to considerable side effects, such as liver toxicity, gastrointestinal and cardiovascular complications (Sostres et al., 2010). Opioids are more potent and effective drugs for patients with refractory pain. Both short and longacting opiates are effective in managing OA pain and have level 3 evidence in their support (Ringdahl and Pandit, 2011). Benefits from the opiates may be acquired, however, frequent adverse effects are associated with these drugs including nausea, dizziness, vomiting, constipation, and sleepiness (Fuggle et al., 2019). In addition, concerns about pharmacologic tolerance, physical dependence suggest the use of opioids should be appropriately dosed and monitored (Lipman, 2001).

There is emerging evidence that IA injections of CSs and HA are helpful for some OA patients (Wernecke et al., 2015; Concoff et al., 2017). CS is known to inhibit the release of inflammatory cytokines in the affected joint and restrain further cartilaginous destruction (Song et al., 2012). IA injections of CSs may provide some patients with temporary symptomatic relief, and a low risk of adverse effects (Wernecke et al., 2015). According to the guideline from Osteoarthritis Research Society International 
TABLE 1 | List of ongoing and completed clinical trials on potential DMOADs.

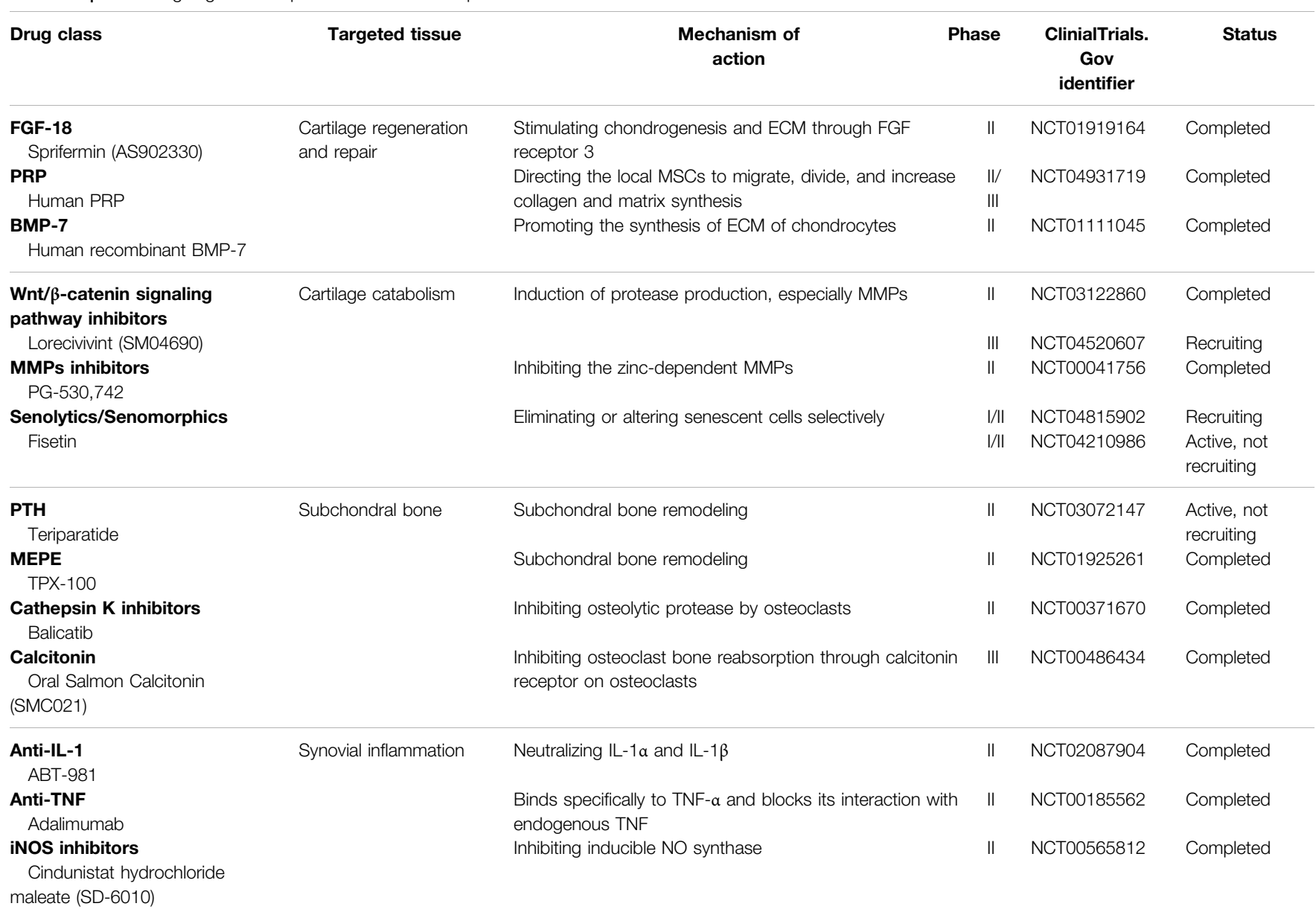

FGF = fibroblast growth factor; $P R P=$ platelet rich plasma; $B M P=$ bone morphogenic protein; $M M P=$ matrix metalloproteinase; $P T H=$ parathyroid hormone; $M E P E=$ matrix extracellular phosphoglycoprotein; IL = interleukin; TNF = tumor necrosis factor; ECM = extracellular matrix; $N O S=$ inducible nitric oxide synthase; NO = nitric oxide.

(OARSI), CSs injections should be performed after patients failing or are unsatisfactory with oral analgesic/antiinflammatory agents, especially for the patients with symptomatic knee OA with effusions or other physical signs of local inflammation (Zhang et al., 2008). HA is a constituent of synovial fluid, while the contents of HA are decreased and compromised in OA joints (Temple-Wong et al., 2016; Chen et al., 2020). Exogenous supplementation of HA is thought to be a visco-supplemental or pharmaceutical therapy for patients with knee OA. They are inferior to CSs in terms of short-term duration, but with likely prolonged symptomatic benefit (Trueba Davalillo et al., 2015). Many complementary medicines (glucosamine sulphate, chondroitin sulphate, ginger, turmeric, etc.) and nutritional supplements have been used to treat OA, but little detail was given and there was no consensus has been achieved (Nelson et al., 2014).

\section{Potential Drugs for OA}

The existing treatments for the management of OA are palliative and often associated with unacceptable side effects. To blunt the epidemic of OA, DMOADs have become a focus of drug development. These products are capable of modifying the structural progression within the joints, as well as ameliorating the symptoms of OA (Ghouri and Conaghan, 2019). These drugs are designed mainly based on the three phenotypes or subpopulations in OA: cartilage, synovial inflammation, and subchondral bone (Oo et al., 2018). DMOADs are largely more targeted than current drugs and can be administered through local injection, which augments the efficacy while diminishing systemic reaction (Hunter and Bierma-Zeinstra, 2019). For example, injectable biologics such as human platelet rich plasma (PRP), Sprifermin (recombinant human fibroblast growth factor 18, rhFGF-18), bone morphogenic protein 7 (BMP7 ), or injectable small molecules and drugs such as WNT signaling pathway inhibitors and MMP inhibitors (Fortier et al., 2011; Glynn et al., 2018; Oo et al., 2018; Mobasheri, 2019). There are significant ongoing efforts in this field, and some of the putative DMOADs are in advanced development (phase II or phase III clinical trials) (Hunter and Bierma-Zeinstra, 2019). Currently, no DMOADs have been licensed by regulatory agencies for use but a number of products have shown promising outcomes in clinical trials (see Table 1). 
Sprifermin (rhFGF-18) acts on FGF receptor 3 in cartilage to stimulate chondrogenesis and ECM production in vivo and in vitro (Reker et al., 2017; Sennett et al., 2018). BMP-7 is a growth factor and has been investigated as a potential drug to repair damaged AC. In addition to the depletion in OA cartilage, BMP-7 also has reparative effects on cartilage by promoting the synthesis of ECM (Thielen et al., 2019). Platelets contain several growth factors, such as insulin-like growth factor-1 (IGF-1), TGF- $\beta$, VEGF, as well as chemokines, cytokines, and numerous soluble proteins (Gato-Calvo et al., 2019). The concentration of platelets in the PRP is 4-6 times higher than that of a healthy person's blood (Qian et al., 2017). It is believed that the clinical efficacy of growth factors could be exerted with PRP, including promoting MSCs recruitment, proliferation, and chondrogenesis (Gato-Calvo et al., 2019). The activation of Wnt/ $\beta$-catenin signalling pathway can also induce cartilage damage by upregulating the expression of catabolic genes, like ADAMTS and MMPs (Oo et al., 2018). Lorecivivint (SM04690) is a smallmolecule Wnt pathway inhibitor and its promising results have been shown in preclinical studies (Deshmukh et al., 2018; Deshmukh et al., 2019). A phase II trial (NCT03122860) conducted on 700 patients for 24 weeks reported a favorable improvement in both pain and function as compared with placebo (Yazici et al., 2021). A small phase-III (NCT04520607) trial is recruiting participants. In addition, senolytics and senomorphics which target pathogenic senescent cells are an emerging therapy for treating aging and chronic diseases (Lagoumtzi and Chondrogianni, 2021). These drugs are also under clinical trials for OA therapy. Fisetin is a polyphenol extracted from fruits and vegetables and has been shown to have senolytic and anti-inflammatory effects (Zheng et al., 2017). Two such clinical trials (NCT04210986, NCT04815902) for Fisetin are underway. Previously, another clinical trial by Unity Biotechnology studying the potential of UBX0101 as a senolytic drug for OA has failed (Hügle and Geurts, 2017). On the other hand, subchondral bone pathologies are indispensable for mediating cartilage damage in OA. Therefore, therapeutic drugs that targeting subchondral bone remodeling is an attractive option for DMOAD development. Teriparatide is a 1-34 amino-acid fragment derived from human parathyroid hormone (PTH) and is normally used as a bone anabolic therapy for osteoporosis. In $\mathrm{OA}$, it displays the ability to stimulate the synthesis of ECM and improve subchondral bone mineral density (Sampson et al., 2011). Matrix extracellular phosphoglycoprotein (MEPE) is a protein that regulates bone and growth plate cartilage mineralization, while TPX-100 is a novel 23-amino-acid peptide that is derived from MEPE (Oo et al., 2018). At the 2020 OARSI conference, it was reported that a significant reduction in pathologic bone shape changes of the femur after IA injection of TPX-100 at 12 months (McGuire et al., 2020). Cathepsin K is a potent osteolytic protease for bone resorption, and cathepsin $\mathrm{K}$ inhibitor has been reported to attenuate cartilage damage in animal models of OA (Hayami et al., 2012). Calcitonin is a hormone secreted by the parafollicular thyroid cells and inhibits osteoclast activity in bone through affecting the calcitonin receptor localized to osteoclasts. Several animal studies have been demonstrated that salmon calcitonin has positive effects on disrupt cartilage degeneration. In a 2-years phase III trial (NCT00486434), oral calcitonin significantly improved knee function in OA patients and enhanced cartilage thickness compared to placebo. IL-1 and TNF- $\alpha$ are the most extensively studied cytokines in preclinical studies. However, most clinical trials investigating the inhibitor of IL- 1 and TNF- $\alpha$ failed to meet symptomatic benefits in OA patients (Oo et al., 2018). Nitric oxide (NO) is an inflammatory mediator and is produced by the inducible NO synthase (iNOS) pathway. Cindunistat hydrochloride maleate (SD-6010) is an orally administered inhibitor of human iNOS, while it failed to show the rate of change in joint space narrowing (JSN) in a 2-years phase II trial (NCT00565812) (Hellio le Graverand et al., 2013).

\section{NON-SURGICAL APPLICATION OF CARTILAGE TISSUE ENGINEERING}

Owing to the avascular nature of cartilage, damaged cartilage has limited capability for healing and repairing by itself (Chen et al., 2017). Therapies, like non- or pharmacologic treatment, only focus on relieving the symptoms of $\mathrm{OA}$, instead of regenerating damaged or degenerative cartilage. These conditions, thus contributing to the emergence of cartilage tissue engineering (CTE), which is come up as a promising strategy for cartilage regeneration by integrating methods and perspectives from life sciences and biomaterials (Ondresik et al., 2017). The goal of CTE is to modify the host microenvironment of OA and promote cartilage regeneration (Ondresik et al., 2017). Successful tissue engineering depends on multiple aspects, including appropriate cells for implantation, well-designed scaffolds for mechanical support, and biological factors for directing cells to differentiate in the proper direction (Liu Y. et al., 2017; Morouco et al., 2019). Recent investigations have highlighted its promising, and some strategies are already available on the market (Brittberg, 2008; Evans et al., 2018).

\section{Cell Injection Therapy}

When it comes to cell therapy, it normally refers to chondrocytes or mesenchymal stem cells (MSCs) based regimen (Phull et al., 2016; Lee and Wang, 2017). Considering the demerits of complicated operation and donor site mobility in chondrocytes-based treatment, MSCs are more prone to be accepted as a fitting source of cells in cell-based therapies (Im, 2018). MSCs are cells of mesodermal origin and progenitors of various cells (osteocytes, chondrocytes, adipocytes, etc.), and can be isolated from diverse tissues, including bone marrow, adipose tissue, placenta, and even peripheral blood (Nejadnik et al., 2015). MSCs have a higher proliferation rate, chondrogenic differentiation capacity and immunomodulatory abilities, which are key features in cartilage regeneration (Gupta et al., 2012). Additionally, the anti-inflammatory and immunosuppressive attributes of MSCs imply that they might inhibit synovial inflammation and reduce pain, as well as can be used as both autografts and allografts for OA patients in clinical trials (Im, 2018). 
TABLE 2 | Animal models using IA injection of MSCs for treating OA.

\begin{tabular}{|c|c|c|c|c|c|c|}
\hline Category & $\begin{array}{l}\text { Cell } \\
\text { source }\end{array}$ & Dose/graft type & $\begin{array}{c}\text { Combination } \\
\text { use }\end{array}$ & Model & Evaluation method & References \\
\hline \multirow[t]{8}{*}{$\begin{array}{l}\text { Small animal } \\
\text { study }\end{array}$} & BM-MSCs & $1^{*} 10^{5} \mathrm{cells} /$ allogeneic & - & mouse & Histology, $\mu \mathrm{CT}$ & $\begin{array}{l}\text { Diekman et al. } \\
\text { (2013) }\end{array}$ \\
\hline & AD-MSCs & $2^{*} 10^{4}$ or $2^{*} 10^{5}$ cells/xenogeneic (equine) & - & mouse & Histology & $\begin{array}{l}\text { Maumus et al. } \\
\text { (2016) }\end{array}$ \\
\hline & SM-MSCs & $1^{*} 10^{6}$ cells/allogeneic & - & mouse & Clinical score, histology & Yan et al. (2017) \\
\hline & BM-MSCs & $\begin{array}{l}6^{*} 10^{5} \text { or } 1.3^{*} 10^{6} \text { cells/xenogeneic } \\
\text { (human) }\end{array}$ & $\mathrm{HA}$ & rat & $\begin{array}{l}\text { Gross morphology, histology, pain } \\
\text { response }\end{array}$ & Gupta et al. (2016) \\
\hline & SM-MSCs & $1^{*} 10^{6}$ cells/xenogeneic (human) & - & rat & Gross morphology, histology, IHC & Ozeki et al. (2016) \\
\hline & UC-MSCs & $1^{*} 10^{5}$ or $1 * 10^{6}$ cells/xenogeneic (human) & Microcryogel & rat & Gross morphology, histology, $\mu \mathrm{CT}$ & Xing et al. (2020) \\
\hline & BM-MSCs & $1^{*} 10^{6}$ cells/allogeneic & $\mathrm{HA}$ & rabbit & Gross morphology, histology, IHC & $\begin{array}{l}\text { Chiang et al. } \\
\text { (2016) }\end{array}$ \\
\hline & AD-MSCs & $2^{*} 10^{6}$ cells/autologous & $\mathrm{HA}$ & rabbit & Gross morphology, histology, IHC & $\begin{array}{l}\text { Kuroda et al. } \\
\text { (2015) }\end{array}$ \\
\hline & AD-MSCs & $1^{*} 10^{7}$ or $5^{\star} 10^{7}$ cells/allogeneic & $\mathrm{HA}$ & sheep & Gross morphology, histology, MRI, $\mu \mathrm{CT}$ & Feng et al. (2018) \\
\hline & AD-MSCs & $\begin{array}{l}1.8^{*} 10^{6}, 6^{*} 10^{6} \text { or } 1.8^{*} 10^{7} \text { cells/ } \\
\text { xenogeneic (human) }\end{array}$ & - & goat & $\begin{array}{l}\text { Histology, macroscopic and micro- } \\
\text { scopic scores }\end{array}$ & Ko et al. (2019) \\
\hline & BM-MSCs & $1^{*} 10^{7}$ cells/autologous & - & horse & Clinical and radiographic scores & Magri et al. (2019) \\
\hline
\end{tabular}

BM-MSCs = bone marrow mesenchymal stem cells; AD-MSCs = adipose-derived mesenchymal stem cells; SM-MSCs = synovial membrane-derived mesenchymal stem cells; UC-MSCs = umbilical cord-derived mesenchymal stem cells; IHC = immunohistochemistry; $H A=$ hyaluronic acid; $M R I=$ magnetic resonance imaging; $\mu C T=$ micro-computed tomography.

\section{MSC-Based Therapy for IA Injection of OA}

The efficacy of MSC-based therapy has been proven to be effective in different OA animal models (Gupta et al., 2012; Grassel and Lorenz, 2014; Sasaki et al., 2019), ranging from murine, rabbit, canine, ovine, and caprine to equine (see Table 2). In vivo study, IA injection of human adipose tissuederived MSCs (AD-MSCs) engrafted into the rat joints and increased the cartilage thickness in surgery-induced OA animal models (Li et al., 2016). Small animal models are often used as a proof-of-concept, owing to their $\mathrm{AC}$ is thinner and smaller than humans. Large animals, such as ovine, equine, or sheep are more suitable for modeling human AC defects and investigating the effectiveness of MSC-based treatments (Grassel and Lorenz, 2014). In a study conducted by Al Faqehand colleagues, autologous bone marrow MSCs (BM-MSCs) were performed for IA injection of surgically-induced OA sheep. 6 weeks after injection, gross evidence of retardation of cartilage destruction was observed in the OA joints treated with BM-MSCs (Al Faqeh et al., 2012). Consistent with this study, the study of Ko et al. found that injected SOX-6, 9transfected AD-MSCs attenuated the progression of $\mathrm{OA}$ in goats (Ko et al., 2019). The safety and feasibility of IA injection of MSCs for cartilage repair have also been evaluated in several clinical trials (Grassel and Lorenz, 2014; Lee and Wang, 2017). It is suggested that subjects with mild to moderate OA (K-L grade 1-3) are optimal candidates for MSC therapy (Lee and Wang, 2017). Jo et al. enrolled 18 patients with knee OA (K-L grade 2-3) and injected autologous AD-MSCs into the knee, showing improved Western Ontario and McMaster Universities Osteoarthritis Index (WOMAC) score, decreased size of the cartilage defect, and increased cartilage volume at 6 months after injection in the high-dose group $\left(1.0 \times 10^{8} / \mathrm{L}\right)$ (Jo et al., 2014). Concomitantly, in a 2 years' follow-up study, Orozco et al. found that IA injection of autologous expanded BM-MSCs was effective in improving both magnetic resonance imaging (MRI) T2 mapping and visual analogue scale (VAS) outcomes in patients undergoing chronic knee pain (Orozco et al., 2013; 2014). In addition, one randomized controlled trial (RCT) study assessing the feasibility and safety of treating OA with allogeneic BM-MSCs was reported by (Vega et al. (2015). In this study, 30 patients with chronic knee OA were randomized into 2 groups of 15 patients: the test group received allogeneic BMMSCs $\left(40 \times 10^{6}\right.$ cells $)$ by IA injection, while the control group received HA (60 mg). After 12 months, the test group illustrated significant improvement in algofunctional indices and quantification of cartilage quality compared to the control group (Vega et al., 2015). Nevertheless, patients withstanding larger cartilage lesions exhibited significantly inferior consequences (Im, 2018). Additionally, MSCs obtained from subjects with severe OA have decreased potential for proliferation and chondrogenic differentiation, resulting in a lower cell yield and higher osteogenic differentiation (Murphy et al., 2002).

\section{Bottleneck of Cell Injection Therapy for OA}

Although encouraging symptomatic relief has been demonstrated in clinical reports, hyaline AC regeneration was rarely reported. In a study with three case reports, Wakitani et al. found that the cartilage defect had been repaired with the fibrocartilaginous tissue in the first patient after 1 year of BM-MSCs transplantation. MRI results of the second patient revealed complete coverage of the defect, while not able to determine the covered materials was 
hyaline cartilage (Wakitani et al., 2007). Discoveries from animal researches implicated that MSCs achieve therapeutic effects in virtue of paracrine mechanisms, rather than integrating with cartilage directly and producing ECM in situ (Saulnier et al., 2015; Ozeki et al., 2016). These paracrine factors consist of various proteins and could be conveyed in extracellular vehicles (EVs) (Lee and Wang, 2017). There are three major categories of EVs: apoptotic bodies, exosomes or nanovesicles, and microparticles/ microvesicles (MPs) (Mianehsaz et al., 2019). Recently, it has been increasingly supported that MSCs-derived exosomes contribute to the reparative effects of MSC-based treatment in OA models (Cosenza et al., 2017) (Zhang et al., 2019). An in vivo study revealed that BM-MSCs and MSCs-derived exosomes equally protected collagenase-induced mice from joint damage (Cosenza et al., 2017). Other issues such as frequency of injection, the dose of MSCs, MSC origin, and transplantation type also should be taken into consideration (Im, 2018). Moreover, the safety of IA injection of MSCs is one of the key points in clinical application. In one meta-analysis, Peeters assessed the reported adverse events of IA treatment with cultured stem cells in humans, four serious adverse effect cases were reported, including one infection, one pulmonary embolism, and two tumors (Peeters et al., 2013). Lastly, a lacking of a large number of multicenter data and high-level evidence hinders the application of MSCs in early-stage OA. Given current knowledge, the preliminary results indicated that IA MSCs injection is promising in reducing pain and improving the quality of OA patients. However, more RCTs and high-level evidence are still required before in-depth clinical translation.

\section{Injectable Hydrogel}

Various natural or synthetic materials have been explored as scaffolds in CTE to create three-dimensional (3D) tissue constructs that maintain and restore the function and structure of the cartilage. In the application of cartilage regeneration, injectable hydrogels over the solid scaffolds initiate the possibility of percutaneous injection, owing to their highly aqueous 3D cross-linked network structure (Wu et al., 2020). Hydrogels are mainly composed of natural biomaterials (chitosan, fibrin, alginate, collagen, and silk), or synthetic materials (polyethylene glycol (PEG), polyvinyl alcohol (PVA), polylactic acid (PLA)) (Liu M. et al., 2017; Li et al., 2019). Their high porosity allows encapsulated cells to adhere, diffuse, and functionally differentiate within the materials. One of the unique superiorities of hydrogels is that they have similar properties to native ECM of cartilage, providing a beneficial growth environment for chondrocytes to maintain their phenotype (Wu et al., 2020). In addition, injectable hydrogels have the ability to gel in situ through controlling some factors such as PH and temperature (Singh et al., 2018). Therefore, it is widely accepted that hydrogel is a potential promising choice for cartilage repair.

\section{Preclinical Studies}

Notably, over the past decade, the cartilage regeneration potential of hydrogels combined with or without cells and biologics have been investigated and remarkable successes have been achieved in fundamental studies (Roberts et al., 2011; Kontturi et al., 2014; Arora et al., 2017). Kontturi et al. designed an injectable, in situ forming type II collagen/HA hydrogel and found that it could assist the long-term survival of the encapsulated chondrocytes as well as maintain their round shape in vitro (Kontturi et al., 2014). In another study, Roberts et al. demonstrated that a chondrocyteladen PEG-LA hydrogel (consisting of PEG and oligomers of lactic acid (LA)) significantly improved the formation of cartilage-like tissue comprised of glycosaminoglycan and collagen under loading (Roberts et al., 2011). Moreover, Arora et al. have reported that TGF- $\beta 1$ loaded hydrogels enhanced cell survival and chondrogenesis of MSCs and chondrocytes (Arora et al., 2017). In parallel, many preclinical studies have assessed the reparative effects of injectable hydrogels on the cartilage in large and small animal models (Na et al., 2007; Wang et al., 2007; Vilela et al., 2015). Na et al. developed a thermo-reversible hydrogel construct blended with HA, which was used as an injectable carrier for rabbit chondrocytes and TGF- $\beta 3$. The results showed that when the blended hydrogels mixed with TGF- $\beta 3$ and chondrocytes were injected subcutaneously into the nude mice, the level of cartilage associated ECM production was significantly higher than those without HA or TGF- $\beta 3$ (Na et al., 2007). Wang et al. used a chondroitin sulphate (CS) based adhesive-hydrogel to stimulate cartilage formation in goat models. This study suggested greater defects fill in the presence of the hydrogels compared to microfracture alone (Wang et al., 2007).

\section{Clinical Trials}

Clinical trials of injectable hydrogels on OA treatment are very limited, and their applications are mainly to boost the efficacy of existing therapies, such as microfracture, osteochondral grafting (Wu et al., 2020). Most of the reported trials are case reports or case series. In a pilot clinical study, Sharma et al. recruited 18 subjects with focal cartilage defects on the medial femoral condyle. 15 subjects (treated group) were treated with the adhesive-hydrogel in conjunction with microfracture, while three subjects (control group) were treated with microfracture alone. At 6 months follow up, MRI analysis showed significant improvement of repair tissue integration was achieved in the treated group. The treated group also experienced pain reduction compared to the controls, and no major adverse events were observed (Sharma et al., 2013). Another clinical trial using ChonDux hydrogel (consisting of a PEG/HA network and a CS adhesive) for treating full-thickness femoral condyle defects (Wolf et al., 2020). Researchers found that ChonDux mediated $94.2 \pm 16.3 \%$ of final defects fill over 2-years of follow-up and the treated tissue was similar to adjacent cartilage between 12 and 24 months, suggesting ChonDux is a safe accessory to microfracture therapy (Wolf et al., 2020). In addition, a novel medicine product (Cartistem), comprised of HA hydrogel and allogeneic human umbilical cord blood-derived MSCs (hUCBMSCs) was assessed in a clinical study over 7-years of follow-up. The results suggested this product appears to be safe and effective for cartilage regeneration in knee OA (Park et al., 2017). The above pilot studies confirmed the prospects of injectable hydrogel in the treatment of OA. However, some challenges for clinical translation remain to be addressed, including the source of the 
material, and integration to the cartilage in a stable way. Future studies are needed to address these issues before clinical application.

\section{Gene-Based Therapy}

As a disease with a great degree of heritability, genetic changes in OA could contribute to defects of a structural component, or imbalance in the metabolism of cartilage and bone (Mobasheri, 2019). In this regard, gene therapy represents an innovative approach to the medical management of OA. It was firstly reported in articulations by Evans et al, who utilized an antiarthritic cytokine (IL-1 Receptor Antagonist, IL-1Ra) gene in human joints with rheumatoid arthritis (RA) (Evans et al., 1996). Unlike the protein-based treatments which have a short half-life, gene therapies aim to establish persistent, endogenous synthesis of the trans-gene products at target sites through IA injection (Mobasheri, 2019). Recently, this has been carried out in vivo and ex vivo studies, using different delivery vectors (non-viral or viral), target genes (growth factors, transcription factors, antiinflammatory cytokines, cell signaling protein $\mathrm{iHH}, \mathrm{ECM}$ protein, integrin- $\beta 1$ ), and cells (stem cells, chondrocytes) with or without biomaterials (Heiligenstein et al., 2011; Shui et al., 2013).

\section{Gene Delivery Strategies}

Delivery of the transgene can be achieved by viral or non-viral methods. At present, viral vectors are more preferred and have been used for IA gene delivery in animal models (Kay et al., 2009; Wang et al., 2016) and human trials (Mease et al., 2009; Mease et al., 2010). Retroviruses and adeno-associated virus (AVV) are the only vectors that have been assayed in clinical studies until now. Compared with other viral vectors, AAV has the advantage of penetrating deeply within cartilage to transduce chondrocytes in situ (Madry et al., 2003). In vivo experiments by Kay et al. showed that the level of IL-1Ra expression present in the joint space of selfcomplementary AAV (sc-AAV) injected rabbits for 2 weeks in sufficient quantities to suppress inflammation of the IL- $1 \beta$-induced arthritis model (Kay et al., 2009). Similarly, in another study, Wang et al. suggested that no local or systemic toxicity was found following sc-AAV vector carrying IL-1Ra transgene (scrAAV2.5IL-1Ra) injection in mono-iodoacetate (MIA)-induced OA rats (Wang et al., 2016). Sustained expression of IL-1Ra and a low rate of cartilage loss were observed in the vectorinjected knees (Wang et al., 2016). In large mammalian joints, transgenic expression of human IL-1Ra could last for 10 weeks at biologically relevant levels following delivery with recombinant AAV in the forelimb joints of horses (Watson et al., 2013). In a phase I clinical trial (NCT00617032), 15 subjects (aged $\geq 18$ years) with inflammatory arthritis (14 with RA and 1 with ankylosing spondylitis) received a single IA injection of $\mathrm{rAAV}-2$ containing a TNF immunoglobulin Fc fusion gene (rAAV2-TNFR:Fc). The result showed that rAAV2-TNFR:Fc appears to be safe and well tolerated in patients not systemically taking TNF- $\alpha$ antagonists (Mease et al., 2009). Furthermore, a phase I/II clinical trial (NCT00126724) on 127 patients (aged 18-75 years) demonstrated that greater improvement in patients treated with rAAV2-TNFR:Fc compared to placebo patients (Mease et al., 2010). Meanwhile, another phase I study (NCT02790723) using
AAV is still in progress and will evaluate the effects of IL-1Ra expression on the OA phenotype (Bellavia et al., 2018).

\section{Selection of Transgene}

Among the numerous target genes, the expressions of GFs and anti-inflammatory cytokines are of interest to researchers and are being assessed in clinical trials (see Table 3). As described aforementioned, IL-1 and TNF- $\alpha$ receptor antagonists are the candidate transgenes with an anti-inflammatory action that have been applied in clinical trials (Mease et al., 2009; Bellavia et al., 2018). TGF- $\beta 1$ is a growth factor that can augment the ability of chondrogenesis of MSCs. Several preliminary studies have confirmed the effects of TGF- $\beta 1$ in the repair of cartilage defects and impeding the chondrocytes hypertrophy (van Caam et al., 2015; Xie et al., 2016). TGF- $\beta 1$ is also the exclusive gene currently being tested in clinical trials for OA treatment (Ondresik et al., 2017). Noh et al. conducted a preclinical study to evaluate the efficacy, biodistribution, and safety of single IA injection of the cell mixture (3:1 ratio of genetically unmodified and TGF- $\beta 1$-secreting human chondrocytes, TG-C) in SCID mice, rabbits, and goats with damaged joints. The results showed that the mixture was tolerated well in all of the species, and cartilage regeneration was present in defects of rabbits and goats (Noh et al., 2010). After these positive pre-clinical results, a phase I clinical trial (NCT00599248) performed on 12 subjects with advanced knee OA suggested that TG-C contributed to an improvement of OA symptoms as well as minor injection site reactions ( $\mathrm{Ha}$ et al., 2012). Concomitantly, a phase II clinical study carried out on 102 patients (NCT01221441) with knee OA, indicated that TG-C treated patients had positive effects on function elevation and pain mitigation compared to placebo at 1-year follow-up (Cherian et al., 2015). Notably, an ex vivo TGF$\beta 1$ gene therapy was authorized in Korea for IA injection of knee joints with moderate-to-severe OA. The product (Invossa ${ }^{\mathrm{TM}}$ ) has received marketing approval in Korea and a phase III clinical trial is expected to begin shortly in the United States (Evans et al., 2018). Other genes, like IGF-1, BMPs, cell signaling protein $\mathrm{iHH}$, ECM component (COMP), and integrin $\beta 1$, are still in their infancy (Bellavia et al., 2018; Tendulkar et al., 2019). Gene combinations are also of interest, and co-infection of IL-1Ra and IGF-1 has a positive effect on repairing cartilage defects in vivo (Morisset et al., 2007).

Gene therapy offers a novel approach to address the issue of transferring exogenous pharmaceuticals into joints topically and durably. Nevertheless, safety and effectiveness are still hurdles for clinical application. Some authors expressed their concerns about the safety of viral vectors, in particular, after the occurrence of severe adverse events such as leukemia and death (Frank et al., 2009). Although these events were not correlated with viral vectors, the proper monitoring for further clinical application needed to be highlighted.

\section{SUMMARY AND FUTURE OUTLOOK}

Recognition of OA is a complex disease with multifactorial nature, and the whole joints are involved in the degenerative 
TABLE 3 | Registered clinical trials on the gene therapy of OA

\begin{tabular}{|c|c|c|c|c|c|c|}
\hline Gene & $\begin{array}{l}\text { Method of } \\
\text { delivery }\end{array}$ & $\begin{array}{l}\text { Number of } \\
\text { participants }\end{array}$ & Evaluations & Phase & $\begin{array}{l}\text { ClinialTrials.gov } \\
\text { identifier }\end{array}$ & Status \\
\hline $\begin{array}{l}\text { TGF- } \\
\beta 1\end{array}$ & $\begin{array}{l}\text { Retrovirus, ex } \\
\text { vivo }\end{array}$ & 12 & $\begin{array}{l}\text { Safety and biological activity of TissueGene-C in degenerative arthritis } \\
\text { patients }\end{array}$ & 1 & NCT00599248 & Completed \\
\hline $\begin{array}{l}\text { TGF- } \\
\beta 1\end{array}$ & $\begin{array}{l}\text { Retrovirus, ex } \\
\text { vivo }\end{array}$ & 12 & Efficacy and safety of TissueGene-C in degenerative arthritis patients & 1 & NCT02341391 & Completed \\
\hline $\begin{array}{l}\text { TGF- } \\
\beta 1\end{array}$ & $\begin{array}{l}\text { Retrovirus, ex } \\
\text { vivo }\end{array}$ & 102 & $\begin{array}{l}\text { Efficacy and safety of TissueGene- } \mathrm{C} \text { in Patients with grade } 3 \text { chronic } \\
\text { degenerative joint disease of the knee }\end{array}$ & $\|$ & NCT01221441 & Completed \\
\hline $\begin{array}{l}\text { TGF- } \\
\beta 1\end{array}$ & $\begin{array}{l}\text { Retrovirus, ex } \\
\text { vivo }\end{array}$ & 28 & Efficacy and safety of TissueGene- $\mathrm{C}$ in degenerative arthritis patients & $\|$ & NCT02341378 & Completed \\
\hline $\begin{array}{l}\text { TGF- } \\
\beta 1\end{array}$ & $\begin{array}{l}\text { Retrovirus, ex } \\
\text { vivo }\end{array}$ & 18 & $\begin{array}{l}\text { Efficacy and safety of TissueGene-C mixed with Fibrin-glue in patients } \\
\text { with degenerative arthritis }\end{array}$ & $\|$ & NCT01825811 & Completed \\
\hline $\begin{array}{l}\text { TGF- } \\
\beta 1\end{array}$ & $\begin{array}{l}\text { Retrovirus, ex } \\
\text { vivo }\end{array}$ & 54 & Efficacy and safety of TissueGene-C in degenerative arthritis patients & $\|$ & NCT01671072 & Completed \\
\hline $\begin{array}{l}\text { TGF- } \\
\beta 1\end{array}$ & $\begin{array}{l}\text { Retrovirus, ex } \\
\text { vivo }\end{array}$ & 163 & Efficacy and safety of TissueGene-C in degenerative arthritis patients & III & NCT02072070 & Completed \\
\hline $\begin{array}{l}\text { TGF- } \\
\beta 1\end{array}$ & $\begin{array}{l}\text { Retrovirus, ex } \\
\text { vivo }\end{array}$ & 510 & Safety and efficacy of TissueGene-C in patients with grade $2-3$ knee OA & III & NCT03203330 & $\begin{array}{l}\text { Active, not } \\
\text { recruiting }\end{array}$ \\
\hline IL-1Ra & $\mathrm{AAV}$, in vivo & 9 & Safety of IA Sc-rAAV2.5IL-1Ra in patients with moderate OA of the Knee & I & NCT02790723 & Recruiting \\
\hline
\end{tabular}

process is crucial for cartilage repair. Therefore, it is necessary to increase our knowledge in basic sciences to comprehensively understand the mechanism of different joint components in OA pathology. Until now, in the clinics, conservative management, including physical measures and pharmacological therapy are still the first choices offered for OA patients. Joint arthroplasties or total replacement surgeries are served as the ultimate therapeutic option to rehabilitate the joint function of patients who withstand severe OA. However, these approaches are not able to induce healing processes or halt the degenerative processes in the joints. Demand for cartilage regeneration remains a big challenge both for clinicians and researchers.

Thanks to the innovations and advances in biomaterials and biotechnology, more and more research efforts have been devoted to studying cartilage repair through non-surgical approaches. Stem cell therapies and injectable hydrogels targeting articular cartilage are being largely explored (Lee and Wang, 2017; Yang et al., 2017). Human clinical trials using IA injection of MSCs have taken place, with more and more pending trials listed on Clinicaltrials.gov (Lee and Wang, 2017). The main problem of cell-based therapy is the chondrogenesis of stem cells is often followed by osteogenesis and hypertrophy. Moreover, increasing evidence demonstrates that the number and life expectancy of injected MSCs in situ is much lower than expected (Sasaki et al., 2019). Significant efforts have been made to address these issues. Excitingly, it was found that the presence of anti-angiogenic factors, such as gremlin-1, chondromoduli-1, and PTH-related protein was able to suppress chondrocyte hypertrophy and enhance MSC chondrogenesis (Vortkamp et al., 1996; Shukunami et al., 2005; Nagai et al., 2010). Recently, advances in the development of cellladen hydrogels have opened up new possibilities for cell therapy.
Cells in hydrogels adhere to and extend on a 3D environment, which is similar to the morphology and distribution of cells in native cartilage (Wu et al., 2020). In addition, hydrogels are usually used as controlled release carriers for bioactive molecules or target drugs. Bioactive molecules, such as growth factors and cytokines, play essential roles in the metabolism and differentiation of chondrocytes (Fortier et al., 2011; Wojdasiewicz et al., 2014). However, it is challenging to maintain the effectiveness of the medicines encapsulated in the hydrogels. In this regard, Spiller et al. have recently developed a hybrid scaffold consisting of degradable poly (lactic-co-glycolic acid) (PLGA) microparticles and PVA hydrogel in which IGF-1 was loaded, resulting in the release of IGF-1 in a sustained manner over 6 weeks (Spiller et al., 2012). Another challenge for injectable hydrogel is how to firmly integrate the hydrogels with local structures, in particular, utilizing an injectable approach. The emergence of gene transfer provides a novel way to solve some of the widespread, demanding, and intractable problems of modern medicine. Theoretically, gene therapy permits longer-lasting, targeted, location-specific expression of a protein of interest, in a more physiologically relevant way. Preclinical studies have confirmed the efficacy and safety of gene therapy and implicated its prospects. Progress towards clinical application appears to be distant, due to the concerns about viral vectors. It is noteworthy that the first gene product, Invossa ${ }^{\mathrm{TM}}$, has received a license in Korea in 2017 (Evans et al., 2018). Its approval will arouse interest in this field to accelerate the development of genetic therapeutics for defective joints.

Overall, each type of treatment has its merits and demerits concerning the application. To date, no technique has indicated the ability to generate native cartilage in the joints. Therefore, to design more efficient therapies that minimize adverse 


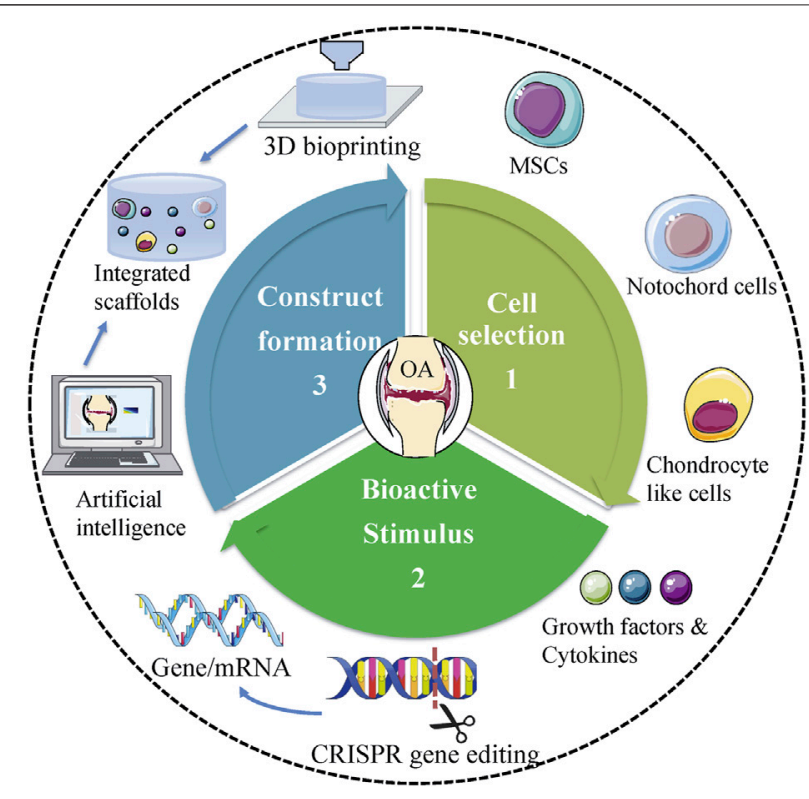

FIGURE 2|Future trends of tissue engineering in treating OA. Proper cell selection, appropriate bioactive stimulus, and perfect design of scaffolds are central to tissue engineering. Novel scientific technologies, including CRISPR gene editing, 3D bioprinting, and Al should be used to facilitate the development of tissue engineering in treating $\mathrm{OA}$.

consequences, it is mandatory to implement interdisciplinary and translational studies. Tissue engineering should be directed to identify the interactions between cells, scaffolds, and the microenvironment of the implant. Recently, Madry et al. designed an injectable and thermosensitive hydrogel on basis of poly (ethylene oxide) (PEO)-poly (propylene oxide) (PPO)-PEO poloxamers, capable of controlling the release of a therapeutic (SOX9) rAAV vector in a clinically relevant minipig model with full-thickness chondral defects (Madry et al., 2020). Four weeks postoperatively, multiple standardized analyses (integration, morphology, matrix staining, and histological scoring of cartilage repair) indicated SOX9/hydrogel construct significantly improved cartilage repair. In addition, the absence of immune cells in all the defects confirmed the benefits of utilizing biomaterial-guided carriers for gene delivery in the clinical application (Madry et al., 2020). Novel scientific technologies would also aid in the development of tissue engineering (Figure 2). CRISPR/Cas9 system is an advanced genomeediting technique that is able to make gene deletion, correction, and substitution, or other changes at specific sites of the genome (Tanikella et al., 2020). For example, CRISPR/Cas9

\section{REFERENCES}

Akkiraju, H., and Nohe, A. (2015). Role of Chondrocytes in Cartilage Formation, Progression of Osteoarthritis and Cartilage Regeneration. J. Dev. Biol. 3 (4), 177-192. doi:10.3390/jdb3040177

Al Faqeh, H., Nor Hamdan, B. M., Chen, H. C., Aminuddin, B. S., and Ruszymah, B. H. (2012). The Potential of Intra-articular Injection of Chondrogenic- has been employed to regulate MMP-13 protein levels and enzymatic activity in human chondrocytes. The results showed CRISPR/Cas9 mediated genome editing significantly reduced the level of MMP-13 protein and enhanced collagen II accumulation (Seidl et al., 2019). On the other hand, advanced manufacturing techniques, such as microfluidic biofabrication, 3D bioprinting are required to fabricate complex tissue constructs (Lopa et al., 2018; Roseti et al., 2018). For example, in order to mimic the nature of AC, Stichler's group utilized a thiol-functionalized HA (HA-SH) hybrid hydrogel embedded with human and equine MSCs as bioink for 3D bioprinting. Embedded MSCs showed a good survival for at least 21 days in vitro culture. Concomitantly, double printing with thermoplastic poly ( $\varepsilon$-caprolactone) (PCL) made the constructs more mechanically stable and robust (Stichler et al., 2017). Furthermore, with the development of machine learning and artificial intelligence (AI), we may be able to accelerate the process of trial and design better materials for cartilage regeneration in the future (Liu et al., 2020).

In conclusion, there is no doubt that tissue engineering has the potential to reproduce the cartilage through a non-operative approach. Despite the relatively successful preclinical investigations and advanced development of clinical trials have been achieved, several hurdles still exist in the routine to the final clinical practice. In particular, ethical concerns and safety issues regarding cell and gene delivery. Another challenge is the precise design of hydrogels with good biocompatibility, excellent biodegradability, and proper mechanical features. Lastly, it is challenging to integrate the hydrogels with the adjacent cartilage tissues in a stable way. Notably, some tissue engineering-based products, like Invossa ${ }^{\mathrm{TM}}$, ChonDux, Cartistem have received marketing approval. It is desirable that these approvals will provoke research interests in this field and therefore accelerate clinical translations in the future.

\section{AUTHOR CONTRIBUTIONS}

TC and JX: conceptual design. TC and WW: data mining and collection. TC and WW: article preparation. WW, YL, AKN, RAW, and JX: article editing. TC, WW, and YL: data interpretation. All authors contributed to the article and approved the submitted version.

\section{ACKNOWLEDGMENTS}

We would like to thank all the authors who contributed to the study.

Induced Bone Marrow Stem Cells to Retard the Progression of Osteoarthritis in a Sheep Model. Exp. Gerontol. 47 (6), 458-464. doi:10.1016/j.exger.2012.03.018

Archer, C. W., and Francis-West, P. (2003). The Chondrocyte. Int. J. Biochem. Cel Biol. 35, 401-404. doi:10.1016/s1357-2725(02)00301-1

Arora, A., Mahajan, A., and Katti, D. S. (2017). TGF- $\beta 1$ Presenting Enzymatically Cross-Linked Injectable Hydrogels for Improved Chondrogenesis. Colloids Surf. B Biointerfaces 159, 838-848. doi:10.1016/j.colsurfb.2017.08.035 
Bellavia, D., Veronesi, F., Carina, V., Costa, V., Raimondi, L., De Luca, A., et al. (2018). Gene Therapy for Chondral and Osteochondral Regeneration: Is the Future Now?. Cell Mol Life Sci 75 (4), 649-667. doi:10.1007/s00018-017-2637-3

Block, J. A. (2014). Osteoarthritis: OA Guidelines: Improving Care or Merely Codifying Practice?. Nat. Rev. Rheumatol. 10 (6), 324-326. doi:10.1038/ nrrheum. 2014.61

Braun, H. J., and Gold, G. E. (2012). Diagnosis of Osteoarthritis: Imaging. Bone 51 (2), 278-288. doi:10.1016/j.bone.2011.11.019

Brittberg, M. (2008). Autologous Chondrocyte Implantation-Ttechnique and Long-Term Follow-Up. Injury 39 Suppl 1, S40-S49. doi:10.1016/ j.injury.2008.01.040

Chen, D., Shen, J., Zhao, W., Wang, T., Han, L., Hamilton, J. L., et al. (2017). Osteoarthritis: toward a Comprehensive Understanding of Pathological Mechanism. Bone Res. 5, 16044. doi:10.1038/boneres.2016.44

Chen, T., Ehnert, S., Tendulkar, G., Zhu, S., Arnscheidt, C., Aspera-Werz, R. H., et al. (2020). Primary Human Chondrocytes Affected by Cigarette SmokeTherapeutic Challenges. Int. J. Mol. Sci. 21 (5), 1901. doi:10.3390/ijms21051901

Cherian, J. J., Parvizi, J., Bramlet, D., Lee, K. H., Romness, D. W., and Mont, M. A. (2015). Preliminary Results of a Phase II Randomized Study to Determine the Efficacy and Safety of Genetically Engineered Allogeneic Human Chondrocytes Expressing TGF- $\beta 1$ in Patients with Grade 3 Chronic Degenerative Joint Disease of the Knee. Osteoarthritis Cartilage 23 (12), 2109-2118. doi:10.1016/j.joca.2015.06.019

Chiang, E. R., Ma, H. L., Wang, J. P., Liu, C. L., Chen, T. H., and Hung, S. C. (2016). Allogeneic Mesenchymal Stem Cells in Combination with Hyaluronic Acid for the Treatment of Osteoarthritis in Rabbits. PLoS One 11 (2), e0149835. doi:10.1371/journal.pone.0149835

Collaborators, G. D. a. I. I. a. P. (2016). Global, Regional, and National Incidence, Prevalence, and Years Lived with Disability for 310 Diseases and Injuries, 19902015: a Systematic Analysis for the Global Burden of Disease Study 2015. Lancet 388 (10053), 1545-1602. doi:10.1016/S0140-6736(16)31678-6

Concoff, A., Sancheti, P., Niazi, F., Shaw, P., and Rosen, J. (2017). The Efficacy of Multiple versus Single Hyaluronic Acid Injections: a Systematic Review and Meta-Analysis. BMC Musculoskelet. Disord. 18 (1), 542. doi:10.1186/s12891017-1897-2

Cosenza, S., Ruiz, M., Toupet, K., Jorgensen, C., and Noël, D. (2017). Mesenchymal Stem Cells Derived Exosomes and Microparticles Protect Cartilage and Bone from Degradation in Osteoarthritis. Sci. Rep. 7 (1), 16214. doi:10.1038/s41598017-15376-8

Deshmukh, V., Hu, H., Barroga, C., Bossard, C., Kc, S., Dellamary, L., et al. (2018). A Small-Molecule Inhibitor of the Wnt Pathway (SM04690) as a Potential Disease Modifying Agent for the Treatment of Osteoarthritis of the Knee. Osteoarthritis Cartilage 26 (1), 18-27. doi:10.1016/j.joca.2017.08.015

Deshmukh, V., O'Green, A. L., Bossard, C., Seo, T., Lamangan, L., Ibanez, M., et al. (2019). Modulation of the Wnt Pathway through Inhibition of CLK2 and DYRK1A by Lorecivivint as a Novel, Potentially Disease-Modifying Approach for Knee Osteoarthritis Treatment. Osteoarthritis Cartilage 27 (9), 1347-1360. doi:10.1016/j.joca.2019.05.006

Diekman, B. O., Wu, C. L., Louer, C. R., Furman, B. D., Huebner, J. L., Kraus, V. B., et al. (2013). Intra-articular Delivery of Purified Mesenchymal Stem Cells from C57BL/6 or MRL/MpJ Superhealer Mice Prevents Posttraumatic Arthritis. Cel Transpl. 22 (8), 1395-1408. doi:10.3727/096368912X653264

Dougados, M. (2006). Why and How to Use NSAIDs in Osteoarthritis. J. Cardiovasc. Pharmacol. 47 Suppl 1, S49-S54. doi:10.1097/00005344200605001-00009

El-Tawil, S., Arendt, E., and Parker, D. (2016). Position Statement: the Epidemiology, Pathogenesis and Risk Factors of Osteoarthritis of the Knee. J. Isakos 1 (4), 219-228. doi:10.1136/jisakos-2015-000002

Evans, C. H., Robbins, P. D., Ghivizzani, S. C., Herndon, J. H., Kang, R., Bahnson, A. B., et al. (1996). Clinical Trial to Assess the Safety, Feasibility, and Efficacy of Transferring a Potentially Anti-arthritic Cytokine Gene to Human Joints with Rheumatoid Arthritis. Hum. Gene Ther. 7 (10), 1261-1280. doi:10.1089/ hum.1996.7.10-1261

Evans, C. H., Ghivizzani, S. C., and Robbins, P. D. (2018). Gene Delivery to Joints by Intra-Articular Injection. Hum. Gene Ther. 29 (1), 2-14. doi:10.1089/ hum.2017.181

Feng, C., Luo, X., He, N., Xia, H., Lv, X., Zhang, X., et al. (2018). Efficacy and Persistence of Allogeneic Adipose-Derived Mesenchymal Stem Cells Combined with Hyaluronic Acid in Osteoarthritis After Intra-articular Injection in a Sheep Model. Tissue Eng. Part. A. 24 (3-4), 219-233. doi:10.1089/ten.tea.2017.0039

Fernandes, J. C., Martel-Pelletier, J., and Pelletier, J. P. (2002). The Role of Cytokines in Osteoarthritis Pathophysiology. Biorheology 39 (1-2), 237-246.

Fortier, L. A., Barker, J. U., Strauss, E. J., McCarrel, T. M., and Cole, B. J. (2011). The Role of Growth Factors in Cartilage Repair. Clin. Orthop. Relat. Res. 469 (10), 2706-2715. doi:10.1007/s11999-011-1857-3

Frank, K. M., Hogarth, D. K., Miller, J. L., Mandal, S., Mease, P. J., Samulski, R. J., et al. (2009). Investigation of the Cause of Death in a Gene-Therapy Trial. $N$. Engl. J. Med. 361 (2), 161-169. doi:10.1056/NEJMoa0801066

Fuggle, N., Curtis, E., Shaw, S., Spooner, L., Bruyère, O., Ntani, G., et al. (2019). Safety of Opioids in Osteoarthritis: Outcomes of a Systematic Review and MetaAnalysis. Drugs Aging 36 (Suppl. 1), 129-143. doi:10.1007/s40266-019-00666-9

Gato-Calvo, L., Magalhaes, J., Ruiz-Romero, C., Blanco, F. J., and Burguera, E. F. (2019). Platelet-rich Plasma in Osteoarthritis Treatment: Review of Current Evidence. Ther. Adv. Chronic Dis. 10, 2040622319825567. doi:10.1177/ 2040622319825567

Ghouri, A., and Conaghan, P. G. (2019). Update on Novel Pharmacological Therapies for Osteoarthritis. Ther. Adv. Musculoskelet. Dis. 11, 1759720X19864492. doi:10.1177/1759720X19864492

Glynn, L. G., Mustafa, A., Casey, M., Krawczyk, J., Blom, J., Galvin, R., et al. (2018). Platelet-rich Plasma (PRP) Therapy for Knee Arthritis: a Feasibility Study in Primary Care. Pilot Feasibility Stud. 4, 93. doi:10.1186/s40814-018-0288-2

Goldring, M. B., and Goldring, S. R. (2007). Osteoarthritis. J. Cel Physiol. 213 (3), 626-634. doi:10.1002/jcp.21258

Grässel, S., and Lorenz, J. (2014). Tissue-engineering Strategies to Repair Chondral and Osteochondral Tissue in Osteoarthritis: Use of Mesenchymal Stem Cells. Curr. Rheumatol. Rep. 16 (10), 452. doi:10.1007/s11926-014-0452-5

Gupta, P. K., Das, A. K., Chullikana, A., and Majumdar, A. S. (2012). Mesenchymal Stem Cells for Cartilage Repair in Osteoarthritis. Stem. Cel. Res. Ther. 3 (4), 25. doi:10.1186/scrt116

Gupta, P. K., Chullikana, A., Rengasamy, M., Shetty, N., Pandey, V., Agarwal, V., et al. (2016). Efficacy and Safety of Adult Human Bone Marrow-Derived, Cultured, Pooled, Allogeneic Mesenchymal Stromal Cells (Stempeucel ${ }^{\circledR}$ ): Preclinical and Clinical Trial in Osteoarthritis of the Knee Joint. Arthritis Res. Ther. 18 (1), 301. doi:10.1186/s13075-016-1195-7

Ha, C. W., Noh, M. J., Choi, K. B., and Lee, K. H. (2012). Initial Phase I Safety of Retrovirally Transduced Human Chondrocytes Expressing Transforming Growth Factor-Beta-1 in Degenerative Arthritis Patients. Cytotherapy 14 (2), 247-256. doi:10.3109/14653249.2011.629645

Hayami, T., Zhuo, Y., Wesolowski, G. A., Pickarski, M., and Duong, L. T. (2012). Inhibition of Cathepsin K Reduces Cartilage Degeneration in the Anterior Cruciate Ligament Transection Rabbit and Murine Models of Osteoarthritis. Bone 50 (6), 1250-1259. doi:10.1016/j.bone.2012.03.025

Heiligenstein, S., Cucchiarini, M., Laschke, M. W., Bohle, R. M., Kohn, D., Menger, M. D., et al. (2011). Evaluation of Nonbiomedical and Biomedical Grade Alginates for the Transplantation of Genetically Modified Articular Chondrocytes to Cartilage Defects in a Large Animal Model In Vivo. J. Gene Med. 13 (4), 230-242. doi:10.1002/jgm.1557

Hellio le Graverand, M. P., Clemmer, R. S., Redifer, P., Brunell, R. M., Hayes, C. W., Brandt, K. D., et al. (2013). A 2-year Randomised, Double-Blind, PlaceboControlled, Multicentre Study of Oral Selective iNOS Inhibitor, Cindunistat (SD-6010), in Patients with Symptomatic Osteoarthritis of the Knee. Ann. Rheum. Dis. 72 (2), 187-195. doi:10.1136/annrheumdis-2012-202239

$\mathrm{Hu}$, Y., Chen, X., Wang, S., Jing, Y., and Su, J. (2021). Subchondral Bone Microenvironment in Osteoarthritis and Pain. Bone Res. 9 (1), 20. doi:10.1038/s41413-021-00147-z

Hügle, T., and Geurts, J. (2017). What Drives Osteoarthritis?-Synovial versus Subchondral Bone Pathology. Rheumatology (Oxford) 56 (9), 1461-1471. doi:10.1093/rheumatology/kew389

Hunter, D. J., and Bierma-Zeinstra, S. (2019). Osteoarthritis. Lancet 393 (10182), 1745-1759. doi:10.1016/s0140-6736(19)30417-9

Hunter, D. J., McDougall, J. J., and Keefe, F. J. (2008). The Symptoms of Osteoarthritis and the Genesis of Pain. Rheum. Dis. Clin. North. Am. 34 (3), 623-643. doi:10.1016/j.rdc.2008.05.004

Im, G. I. (2018). Tissue Engineering in Osteoarthritis: Current Status and Prospect of Mesenchymal Stem Cell Therapy. BioDrugs 32 (3), 183-192. doi:10.1007/ s40259-018-0276-3 
Jia, Z., Liu, Q., Liang, Y., Li, X., Xu, X., Ouyang, K., et al. (2018). Repair of Articular Cartilage Defects with Intra-articular Injection of Autologous Rabbit Synovial Fluid-Derived Mesenchymal Stem Cells. J. Transl Med. 16 (1), 123. doi:10.1186/ s12967-018-1485-8

Jo, C. H., Lee, Y. G., Shin, W. H., Kim, H., Chai, J. W., Jeong, E. C., et al. (2014). Intra-articular Injection of Mesenchymal Stem Cells for the Treatment of Osteoarthritis of the Knee: a Proof-Of-Concept Clinical Trial. Stem Cells 32 (5), 1254-1266. doi:10.1002/stem.1634

Jordan, K. M., Arden, N. K., Doherty, M., Bannwarth, B., Bijlsma, J. W., Dieppe, P., et al. (2003). EULAR Recommendations 2003: an Evidence Based Approach to the Management of Knee Osteoarthritis: Report of a Task Force of the Standing Committee for International Clinical Studies Including Therapeutic Trials (ESCISIT). Ann. Rheum. Dis. 62 (12), 1145-1155. doi:10.1136/ard.2003.011742

Kay, J. D., Gouze, E., Oligino, T. J., Gouze, J. N., Watson, R. S., Levings, P. P., et al. (2009). Intra-articular Gene Delivery and Expression of interleukin-1Ra Mediated by Self-Complementary Adeno-Associated Virus. J. Gene Med. 11 (7), 605-614. doi:10.1002/jgm.1334

Ko, J. Y., Lee, J., Lee, J., Ryu, Y. H., and Im, G. I. (2019). SOX-6, 9-Transfected Adipose Stem Cells to Treat Surgically-Induced Osteoarthritis in Goats. Tissue Eng. Part. A. 25 (13-14), 990-1000. doi:10.1089/ten.TEA.2018.0189

Kontturi, L. S., Järvinen, E., Muhonen, V., Collin, E. C., Pandit, A. S., Kiviranta, I., et al. (2014). An Injectable, In Situ Forming Type II Collagen/hyaluronic Acid Hydrogel Vehicle for Chondrocyte Delivery in Cartilage Tissue Engineering. Drug Deliv. Transl Res. 4 (2), 149-158. doi:10.1007/s13346-013-0188-1

Kuroda, K., Kabata, T., Hayashi, K., Maeda, T., Kajino, Y., Iwai, S., et al. (2015). The Paracrine Effect of Adipose-Derived Stem Cells Inhibits Osteoarthritis Progression. BMC Musculoskelet. Disord. 16, 236. doi:10.1186/s12891-0150701-4

Lagoumtzi, S. M., and Chondrogianni, N. (2021). Senolytics and Senomorphics: Natural and Synthetic Therapeutics in the Treatment of Aging and Chronic Diseases. Free Radic. Biol. Med. 171, 169-190. doi:10.1016/ j.freeradbiomed.2021.05.003

Lee, W. Y., and Wang, B. (2017). Cartilage Repair by Mesenchymal Stem Cells: Clinical Trial Update and Perspectives. J. Orthop. Translat 9, 76-88. doi:10.1016/j.jot.2017.03.005

Li, M., Luo, X., Lv, X., Liu, V., Zhao, G., Zhang, X., et al. (2016). In Vivo human Adipose-Derived Mesenchymal Stem Cell Tracking after Intra-articular Delivery in a Rat Osteoarthritis Model. Stem. Cel. Res. Ther. 7 (1), 160. doi:10.1186/s13287-016-0420-2

Li, L., Duan, X., Fan, Z., Chen, L., Xing, F., Xu, Z., et al. (2018). Mesenchymal Stem Cells in Combination with Hyaluronic Acid for Articular Cartilage Defects. Sci. Rep. 8 (1), 9900. doi:10.1038/s41598-018-27737-y

Li, J., Chen, G., Xu, X., Abdou, P., Jiang, Q., Shi, D., et al. (2019). Advances of Injectable Hydrogel-Based Scaffolds for Cartilage Regeneration. Regen. Biomater. 6 (3), 129-140. doi:10.1093/rb/rbz022

Lipman, A. G. (2001). Treatment of Chronic Pain in Osteoarthritis: Do Opioids Have a Clinical Role?. Curr. Rheumatol. Rep. 3 (6), 513-519. doi:10.1007/ s11926-001-0066-6

Liu, M., Zeng, X., Ma, C., Yi, H., Ali, Z., Mou, X., et al. (2017a). Injectable Hydrogels for Cartilage and Bone Tissue Engineering. Bone Res. 5, 17014. doi:10.1038/ boneres.2017.14

Liu, Y., Zhou, G., and Cao, Y. (2017b). Recent Progress in Cartilage Tissue Engineering-Our Experience and Future Directions. Engineering 3 (1), 28-35. doi:10.1016/j.eng.2017.01.010

Liu, Y. Y. F., Lu, Y., Oh, S., and Conduit, G. J. (2020). Machine Learning to Predict Mesenchymal Stem Cell Efficacy for Cartilage Repair. Plos Comput. Biol. 16 (10), e1008275. doi:10.1371/journal.pcbi.1008275

Lopa, S., Mondadori, C., Mainardi, V. L., Talò, G., Costantini, M., Candrian, C., et al. (2018). Translational Application of Microfluidics and Bioprinting for Stem Cell-Based Cartilage Repair. Stem Cell Int. 2018, 6594841. doi:10.1155/ 2018/6594841

Madry, H., Cucchiarini, M., Terwilliger, E. F., and Trippel, S. B. (2003). Recombinant Adeno-Associated Virus Vectors Efficiently and Persistently Transduce Chondrocytes in normal and Osteoarthritic Human Articular Cartilage. Hum. Gene Ther. 14 (4), 393-402. doi:10.1089/104303403321208998

Madry, H., Gao, L., Rey-Rico, A., Venkatesan, J. K., Müller-Brandt, K., Cai, X., et al. (2020). Thermosensitive Hydrogel Based on PEO-PPO-PEO Poloxamers for a Controlled In Situ Release of Recombinant Adeno-Associated Viral Vectors for
Effective Gene Therapy of Cartilage Defects. Adv. Mater. 32 (2), e1906508. doi:10.1002/adma.201906508

Magri, C., Schramme, M., Febre, M., Cauvin, E., Labadie, F., Saulnier, N., et al. (2019). Comparison of Efficacy and Safety of Single versus Repeated Intraarticular Injection of Allogeneic Neonatal Mesenchymal Stem Cells for Treatment of Osteoarthritis of the Metacarpophalangeal/ metatarsophalangeal Joint in Horses: A Clinical Pilot Study. PLoS One 14 (8), e0221317. doi:10.1371/journal.pone.0221317

March, L., Smith, E. U., Hoy, D. G., Cross, M. J., Sanchez-Riera, L., Blyth, F., et al. (2014). Burden of Disability Due to Musculoskeletal (MSK) Disorders. Best Pract. Res. Clin. Rheumatol. 28 (3), 353-366. doi:10.1016/j.berh.2014.08.002

Maumus, M., Roussignol, G., Toupet, K., Penarier, G., Bentz, I., Teixeira, S., et al. (2016). Utility of a Mouse Model of Osteoarthritis to Demonstrate Cartilage Protection by IFN $\gamma$-Primed Equine Mesenchymal Stem Cells. Front. Immunol. 7, 392. doi:10.3389/fimmu.2016.00392

McGuire, D., Bowes, M., Brett, A., Miller, M., and Kumugai, Y. (2020). Study TPX100-5: Significant Reduction in Femoral Bone Shape Change 12 Months after IA TPX-100 Correlates with Tibiofemoral Cartilage Stabilization. Osteoarthritis Cartilage 28, S37-S38. doi:10.1016/j.joca.2020.02.062

Mease, P. J., Hobbs, K., Chalmers, A., El-Gabalawy, H., Bookman, A., Keystone, E., et al. (2009). Local Delivery of a Recombinant Adenoassociated Vector Containing a Tumour Necrosis Factor Alpha Antagonist Gene in Inflammatory Arthritis: a Phase 1 Dose-Escalation Safety and Tolerability Study. Ann. Rheum. Dis. 68 (8), 1247-1254. doi:10.1136/ard.2008.089375

Mease, P. J., Wei, N., Fudman, E. J., Kivitz, A. J., Schechtman, J., Trapp, R. G., et al. (2010). Safety, Tolerability, and Clinical Outcomes after Intraarticular Injection of a Recombinant Adeno-Associated Vector Containing a Tumor Necrosis Factor Antagonist Gene: Results of a Phase 1/2 Study. J. Rheumatol. 37 (4), 692-703. doi:10.3899/jrheum.090817

Messier, S. P. (2009). Obesity and Osteoarthritis: Disease Genesis and Nonpharmacologic Weight Management. Med. Clin. North. Am. 93 (1), 145-xii. xi-xii. doi:10.1016/j.mcna.2008.09.011

Mianehsaz, E., Mirzaei, H. R., Mahjoubin-Tehran, M., Rezaee, A., Sahebnasagh, R., Pourhanifeh, M. H., et al. (2019). Mesenchymal Stem Cell-Derived Exosomes: a New Therapeutic Approach to Osteoarthritis? Stem. Cel. Res. Ther. 10 (1), 340. doi:10.1186/s13287-019-1445-0

Mobasheri, A. (2019). Future Cell and Gene Therapy for Osteoarthritis (OA): Potential for Using Mammalian Protein Production Platforms, Irradiated and Transfected Protein Packaging Cell Lines for Over-Production of Therapeutic Proteins and Growth Factors. Adv. Exp. Med. Biol. 1247, 17-31. doi:10.1007/ 5584_2019_457

Morisset, S., Frisbie, D. D., Robbins, P. D., Nixon, A. J., and McIlwraith, C. W. (2007). IL-1ra/IGF-1 Gene Therapy Modulates Repair of Microfractured Chondral Defects. Clin. Orthop. Relat. Res. 462, 221-228. doi:10.1097/ BLO.0b013e3180dca05f

Morouço, P., Fernandes, C., and Santos-Rocha, R. (2019). Osteoarthritis, Exercise, and Tissue Engineering: A Stimulating Triad for Health Professionals. J. Aging Res. 2019, 1935806. doi:10.1155/2019/1935806

Murphy, J. M., Dixon, K., Beck, S., Fabian, D., Feldman, A., and Barry, F. (2002). Reduced Chondrogenic and Adipogenic Activity of Mesenchymal Stem Cells from Patients with Advanced Osteoarthritis. Arthritis Rheum. 46 (3), 704-713. doi:10.1002/art.10118

Na, K., Kim, S., Woo, D. G., Sun, B. K., Yang, H. N., Chung, H. M., et al. (2007). Synergistic Effect of TGFbeta-3 on Chondrogenic Differentiation of Rabbit Chondrocytes in Thermo-Reversible Hydrogel Constructs Blended with Hyaluronic Acid by In Vivo Test. J. Biotechnol. 128 (2), 412-422. doi:10.1016/j.jbiotec.2006.09.025

Nagai, T., Sato, M., Kutsuna, T., Kokubo, M., Ebihara, G., Ohta, N., et al. (2010). Intravenous Administration of Anti-vascular Endothelial Growth Factor Humanized Monoclonal Antibody Bevacizumab Improves Articular Cartilage Repair. Arthritis Res. Ther. 12 (5), R178. doi:10.1186/ar3142

Nejadnik, H., Diecke, S., Lenkov, O. D., Chapelin, F., Donig, J., Tong, X., et al. (2015). Improved Approach for Chondrogenic Differentiation of Human Induced Pluripotent Stem Cells. Stem Cel Rev Rep 11 (2), 242-253. doi:10.1007/s12015-014-9581-5

Nelson, A. E., Allen, K. D., Golightly, Y. M., Goode, A. P., and Jordan, J. M. (2014). A Systematic Review of Recommendations and Guidelines for the Management of Osteoarthritis: The Chronic Osteoarthritis Management Initiative of the U.S. 
Bone and Joint Initiative. Semin. Arthritis Rheum. 43 (6), 701-712. doi:10.1016/ j.semarthrit.2013.11.012

Noh, M. J., Copeland, R. O., Yi, Y., Choi, K. B., Meschter, C., Hwang, S., et al. (2010). Pre-clinical Studies of Retrovirally Transduced Human Chondrocytes Expressing Transforming Growth Factor-Beta-1 (TG-C). Cytotherapy 12 (3), 384-393. doi:10.3109/14653240903470639

Ondrésik, M., Azevedo Maia, F. R., da Silva Morais, A., Gertrudes, A. C., Dias Bacelar, A. H., Correia, C., et al. (2017). Management of Knee Osteoarthritis. Current Status and Future Trends. Biotechnol. Bioeng. 114 (4), 717-739. doi:10.1002/bit.26182

Oo, W. M., Yu, S. P., Daniel, M. S., and Hunter, D. J. (2018). Disease-Modifying Drugs in Osteoarthritis: Current Understanding and Future Therapeutics. Expert Opin. Emerg. Drugs 23 (4), 331-347. doi:10.1080/ 14728214.2018.1547706

Orozco, L., Munar, A., Soler, R., Alberca, M., Soler, F., Huguet, M., et al. (2013). Treatment of Knee Osteoarthritis with Autologous Mesenchymal Stem Cells: a Pilot Study. Transplantation 95 (12), 1535-1541. doi:10.1097/ TP.0b013e318291a2da

Orozco, L., Munar, A., Soler, R., Alberca, M., Soler, F., Huguet, M., et al. (2014). Treatment of Knee Osteoarthritis with Autologous Mesenchymal Stem Cells: Two-Year Follow-Up Results. Transplantation 97 (11), e66-8. doi:10.1097/ tp.0000000000000167

Ozeki, N., Muneta, T., Koga, H., Nakagawa, Y., Mizuno, M., Tsuji, K., et al. (2016). Not single but Periodic Injections of Synovial Mesenchymal Stem Cells Maintain Viable Cells in Knees and Inhibit Osteoarthritis Progression in Rats. Osteoarthritis Cartilage 24 (6), 1061-1070. doi:10.1016/j.joca.2015.12.018

Park, Y. B., Ha, C. W., Lee, C. H., Yoon, Y. C., and Park, Y. G. (2017). Cartilage Regeneration in Osteoarthritic Patients by a Composite of Allogeneic Umbilical Cord Blood-Derived Mesenchymal Stem Cells and Hyaluronate Hydrogel: Results from a Clinical Trial for Safety and Proof-Of-Concept with 7 Years of Extended Follow-Up. Stem Cell Transl Med. 6 (2), 613-621. doi:10.5966/ sctm.2016-0157

Peeters, C. M., Leijs, M. J., Reijman, M., van Osch, G. J., and Bos, P. K. (2013). Safety of Intra-articular Cell-Therapy with Culture-Expanded Stem Cells in Humans: a Systematic Literature Review. Osteoarthritis Cartilage 21 (10), 1465-1473. doi:10.1016/j.joca.2013.06.025

Phull, A. R., Eo, S. H., Abbas, Q., Ahmed, M., and Kim, S. J. (2016). Applications of Chondrocyte-Based Cartilage Engineering: An Overview. Biomed. Res. Int. 2016, 1879837. doi:10.1155/2016/1879837

Qian, Y., Han, Q., Chen, W., Song, J., Zhao, X., Ouyang, Y., et al. (2017). Platelet-Rich Plasma Derived Growth Factors Contribute to Stem Cell Differentiation in Musculoskeletal Regeneration. Front. Chem. 5, 89. doi:10.3389/fchem.2017.00089

Reker, D., Kjelgaard-Petersen, C. F., Siebuhr, A. S., Michaelis, M., Gigout, A., Karsdal, M. A., et al. (2017). Sprifermin (rhFGF18) Modulates Extracellular Matrix Turnover in Cartilage Explants Ex Vivo. J. Transl Med. 15 (1), 250. doi:10.1186/s12967-017-1356-8

Ringdahl, E., and Pandit, S. (2011). Treatment of Knee Osteoarthritis. Am. Fam. Physician 83 (11), 1287-1292.

Roberts, J. J., Nicodemus, G. D., Greenwald, E. C., and Bryant, S. J. (2011). Degradation Improves Tissue Formation in (Un)loaded Chondrocyte-Laden Hydrogels. Clin. Orthop. Relat. Res. 469 (10), 2725-2734. doi:10.1007/s11999011-1823-0

Rönn, K., Reischl, N., Gautier, E., and Jacobi, M. (2011). Current Surgical Treatment of Knee Osteoarthritis. Arthritis 2011, 454873. doi:10.1155/2011/ 454873

Roseti, L., Cavallo, C., Desando, G., Parisi, V., Petretta, M., Bartolotti, I., et al. (2018). Three-Dimensional Bioprinting of Cartilage by the Use of Stem Cells: A Strategy to Improve Regeneration. Materials (Basel) 11 (9), 1749. doi:10.3390/ ma11091749

Sampson, E. R., Hilton, M. J., Tian, Y., Chen, D., Schwarz, E. M., Mooney, R. A., et al. (2011). Teriparatide as a Chondroregenerative Therapy for InjuryInduced Osteoarthritis. Sci. Transl Med. 3 (101), 101ra93. doi:10.1126/ scitranslmed.3002214

Sasaki, A., Mizuno, M., Mochizuki, M., and Sekiya, I. (2019). Mesenchymal Stem Cells for Cartilage Regeneration in Dogs. World J. Stem Cell 11 (5), 254-269. doi:10.4252/wjsc.v11.i5.254

Sato, M., Uchida, K., Nakajima, H., Miyazaki, T., Guerrero, A. R., Watanabe, S., et al. (2012). Direct Transplantation of Mesenchymal Stem Cells into the Knee
Joints of Hartley Strain guinea Pigs with Spontaneous Osteoarthritis. Arthritis Res. Ther. 14 (1), R31. doi:10.1186/ar3735

Saulnier, N., Viguier, E., Perrier-Groult, E., Chenu, C., Pillet, E., Roger, T., et al. (2015). Intra-articular Administration of Xenogeneic Neonatal Mesenchymal Stromal Cells Early after Meniscal Injury Down-Regulates Metalloproteinase Gene Expression in Synovium and Prevents Cartilage Degradation in a Rabbit Model of Osteoarthritis. Osteoarthritis Cartilage 23 (1), 122-133. doi:10.1016/ j.joca.2014.09.007

Scanzello, C. R., and Goldring, S. R. (2012). The Role of Synovitis in Osteoarthritis Pathogenesis. Bone 51 (2), 249-257. doi:10.1016/j.bone.2012.02.012

Seidl, C. I., Fulga, T. A., and Murphy, C. L. (2019). CRISPR-Cas9 Targeting of MMP13 in Human Chondrocytes Leads to Significantly Reduced Levels of the Metalloproteinase and Enhanced Type II Collagen Accumulation. Osteoarthritis Cartilage 27 (1), 140-147. doi:10.1016/j.joca.2018.09.001

Sennett, M. L., Meloni, G. R., Farran, A. J. E., Guehring, H., Mauck, R. L., and Dodge, G. R. (2018). Sprifermin Treatment Enhances Cartilage Integration in an In Vitro Repair Model. J. Orthop. Res. 36 (10), 2648-2656. doi:10.1002/jor.24048

Sharma, B., Fermanian, S., Gibson, M., Unterman, S., Herzka, D. A., Cascio, B., et al. (2013). Human Cartilage Repair with a Photoreactive Adhesive-Hydrogel Composite. Sci. Transl Med. 5 (167), 167ra6. doi:10.1126/scitranslmed.3004838

Shui, W., Yin, L., Luo, J., Li, R., Zhang, W., Zhang, J., et al. (2013). Characterization of Chondrocyte Scaffold Carriers for Cell-Based Gene Therapy in Articular Cartilage Repair. J. Biomed. Mater. Res. A. 101 (12), 3542-3550. doi:10.1002/ jbm.a.34661

Shukunami, C., Oshima, Y., and Hiraki, Y. (2005). Chondromodulin-I and Tenomodulin: a New Class of Tissue-specific Angiogenesis Inhibitors Found in Hypovascular Connective Tissues. Biochem. Biophys. Res. Commun. 333 (2), 299-307. doi:10.1016/j.bbrc.2005.05.133

Silverwood, V., Blagojevic-Bucknall, M., Jinks, C., Jordan, J. L., Protheroe, J., and Jordan, K. P. (2015). Current Evidence on Risk Factors for Knee Osteoarthritis in Older Adults: a Systematic Review and Meta-Analysis. Osteoarthritis Cartilage 23 (4), 507-515. doi:10.1016/j.joca.2014.11.019

Sims, N. A., and Martin, T. J. (2020). Osteoclasts Provide Coupling Signals to Osteoblast Lineage Cells Through Multiple Mechanisms. Annu. Rev. Physiol. 82, 507-529. doi:10.1146/annurev-physiol-021119-034425

Singh, Y. P., Moses, J. C., Bhardwaj, N., and Mandal, B. B. (2018). Injectable Hydrogels: A New Paradigm for Osteochondral Tissue Engineering. J. Mater. Chem. B. 6 (35), 5499-5529. doi:10.1039/c8tb01430b

Song, Y. W., Zhang, T., and Wang, W. B. (2012). Gluococorticoid Could Influence Extracellular Matrix Synthesis Through Sox9 via P38 MAPK Pathway. Rheumatol. Int. 32 (11), 3669-3673. doi:10.1007/s00296-011-2091-8

Sophia Fox, A. J., Bedi, A., and Rodeo, S. A. (2009). The Basic Science of Articular Cartilage: Structure, Composition, and Function. Sports Health 1 (6), 461-468. doi:10.1177/1941738109350438

Sostres, C., Gargallo, C. J., Arroyo, M. T., and Lanas, A. (2010). Adverse Effects of Non-Steroidal Anti-Inflammatory Drugs (NSAIDs, Aspirin and Coxibs) on Upper Gastrointestinal Tract. Best Pract. Res. Clin. Gastroenterol. 24 (2), 121-132. doi:10.1016/j.bpg.2009.11.005

Spiller, K. L., Liu, Y., Holloway, J. L., Maher, S. A., Cao, Y., Liu, W., et al. (2012). A Novel Method for the Direct Fabrication of Growth Factor-Loaded Microspheres within Porous Nondegradable Hydrogels: Controlled Release for Cartilage Tissue Engineering. J. Control. Release 157 (1), 39-45. doi:10.1016/ j.jconrel.2011.09.057

Stichler, S., Böck, T., Paxton, N., Bertlein, S., Levato, R., Schill, V., et al. (2017). Double Printing of Hyaluronic Acid/poly(glycidol) Hybrid Hydrogels with Poly( $\varepsilon$-Caprolactone) for MSC Chondrogenesis. Biofabrication 9 (4), 044108. doi:10.1088/1758-5090/aa8cb7

Tanikella, A. S., Hardy, M. J., Frahs, S. M., Cormier, A. G., Gibbons, K. D., Fitzpatrick, C. K., et al. (2020). Emerging Gene-Editing Modalities for Osteoarthritis. Int. J. Mol. Sci. 21 (17), 6046. doi:10.3390/ijms21176046

Temple-Wong, M. M., Ren, S., Quach, P., Hansen, B. C., Chen, A. C., Hasegawa, A., et al. (2016). Hyaluronan Concentration and Size Distribution in Human Knee Synovial Fluid: Variations with Age and Cartilage Degeneration. Arthritis Res. Ther. 18, 18. doi:10.1186/s13075-016-0922-4

Tendulkar, G., Ehnert, S., Sreekumar, V., Chen, T., Kaps, H. P., Golombek, S., et al. (2019). Exogenous Delivery of Link N mRNA into Chondrocytes and MSCsThe Potential Role in Increasing Anabolic Response. Int. J. Mol. Sci. 20 (7), 1716. doi:10.3390/ijms20071716 
Thielen, N. G. M., van der Kraan, P. M., and van Caam, A. P. M. (2019). TGF $\beta /$ BMP Signaling Pathway in Cartilage Homeostasis. Cells 8 (9), 969. doi:10.3390/ cells8090969

Thomas, S., Browne, H., Mobasheri, A., and Rayman, M. P. (2018). What Is the Evidence for a Role for Diet and Nutrition in Osteoarthritis?. Rheumatology (Oxford) 57 (Suppl. 1_4), iv61-iv74. doi:10.1093/rheumatology/key011

Trueba Davalillo, C. Á., Trueba Vasavilbaso, C., Navarrete Álvarez, J. M., Coronel Granado, P., García Jiménez, O. A., Gimeno Del Sol, M., et al. (2015). Clinical Efficacy of Intra-articular Injections in Knee Osteoarthritis: a Prospective Randomized Study Comparing Hyaluronic Acid and Betamethasone. Open Access Rheumatol. 7, 9-18. doi:10.2147/OARRR.S74553

van Caam, A., Blaney Davidson, E., Garcia de Vinuesa, A., van Geffen, E., van den Berg, W., Goumans, M. J., et al. (2015). The High Affinity ALK1-Ligand BMP9 Induces a Hypertrophy-like State in Chondrocytes that Is Antagonized by TGF $\beta 1$. Osteoarthritis Cartilage 23 (6), 985-995. doi:10.1016/ j.joca.2015.02.007

Vega, A., Martín-Ferrero, M. A., Del Canto, F., Alberca, M., García, V., Munar, A., et al. (2015). Treatment of Knee Osteoarthritis with Allogeneic Bone Marrow Mesenchymal Stem Cells: A Randomized Controlled Trial. Transplantation 99 (8), 1681-1690. doi:10.1097/tp.0000000000000678

Vilela, C. A., Correia, C., Oliveira, J. M., Sousa, R. A., Espregueira-Mendes, J., and Reis, R. L. (2015). Cartilage Repair Using Hydrogels: A Critical Review of In Vivo Experimental Designs. ACS Biomater. Sci. Eng. 1 (9), 726-739. doi:10.1021/acsbiomaterials.5b00245

Vortkamp, A., Lee, K., Lanske, B., Segre, G. V., Kronenberg, H. M., and Tabin, C. J. (1996). Regulation of Rate of Cartilage Differentiation by Indian Hedgehog and PTH-Related Protein. Science 273 (5275), 613-622. doi:10.1126/ science.273.5275.613

Wakitani, S., Nawata, M., Tensho, K., Okabe, T., Machida, H., and Ohgushi, H. (2007). Repair of Articular Cartilage Defects in the Patello-Femoral Joint with Autologous Bone Marrow Mesenchymal Cell Transplantation: Three Case Reports Involving Nine Defects in Five Knees. J. Tissue Eng. Regen. Med. 1 (1), 74-79. doi:10.1002/term.8

Wang, D. A., Varghese, S., Sharma, B., Strehin, I., Fermanian, S., Gorham, J., et al. (2007). Multifunctional Chondroitin Sulphate for Cartilage Tissue-Biomaterial Integration. Nat. Mater. 6 (5), 385-392. doi:10.1038/nmat1890

Wang, G., Evans, C. H., Benson, J. M., Hutt, J. A., Seagrave, J., Wilder, J. A., et al. (2016). Safety and Biodistribution Assessment of sc-rAAV2.5IL-1Ra Administered via Intra-articular Injection in a Mono-IodoacetateInduced Osteoarthritis Rat Model. Mol. Ther. Methods Clin. Dev. 3, 15052. doi:10.1038/mtm.2015.52

Watson, R. S., Broome, T. A., Levings, P. P., Rice, B. L., Kay, J. D., Smith, A. D., et al. (2013). scAAV-Mediated Gene Transfer of Interleukin-1-Receptor Antagonist to Synovium and Articular Cartilage in Large Mammalian Joints. Gene Ther. 20 (6), 670-677. doi:10.1038/gt.2012.81

Wernecke, C., Braun, H. J., and Dragoo, J. L. (2015). The Effect of Intra-articular Corticosteroids on Articular Cartilage: A Systematic Review. Orthop. J. Sports Med. 3 (5), 2325967115581163. doi:10.1177/2325967115581163

Wojdasiewicz, P., Poniatowski, Ł. A., and Szukiewicz, D. (2014). The Role of Inflammatory and Anti-inflammatory Cytokines in the Pathogenesis of Osteoarthritis. Mediators Inflamm. 2014, 561459. doi:10.1155/2014/561459

Wolf, M. T., Zhang, H., Sharma, B., Marcus, N. A., Pietzner, U., Fickert, S., et al. (2020). Two-Year Follow-Up and Remodeling Kinetics of ChonDux Hydrogel for Full-Thickness Cartilage Defect Repair in the Knee. Cartilage 11 (4), 447-457. doi:10.1177/1947603518800547

Wu, J., Chen, Q., Deng, C., Xu, B., Zhang, Z., Yang, Y., et al. (2020). Exquisite Design of Injectable Hydrogels in Cartilage Repair. Theranostics 10 (21), 9843-9864. doi: 10.7150/thno.46450
Xie, L., Tintani, F., Wang, X., Li, F., Zhen, G., Qiu, T., et al. (2016). Systemic Neutralization of TGF- $\beta$ Attenuates Osteoarthritis. Ann. N. Y Acad. Sci. 1376 (1), 53-64. doi:10.1111/nyas.13000

Xing, D., Liu, W., Wang, B., Li, J. J., Zhao, Y., Li, H., et al. (2020). Intra-articular Injection of Cell-Laden 3D Microcryogels Empower Low-Dose Cell Therapy for Osteoarthritis in a Rat Model. Cel Transpl. 29, 963689720932142. doi:10.1177/ 0963689720932142

Yan, M., Liu, X., Dang, Q., Huang, H., Yang, F., and Li, Y. (2017). Intra-Articular Injection of Human Synovial Membrane-Derived Mesenchymal Stem Cells in Murine Collagen-Induced Arthritis: Assessment of Immunomodulatory Capacity In Vivo. Stem Cell Int. 2017, 9198328. doi:10.1155/2017/9198328

Yang, J., Zhang, Y. S., Yue, K., and Khademhosseini, A. (2017). Cell-laden Hydrogels for Osteochondral and Cartilage Tissue Engineering. Acta Biomater. 57, 1-25. doi:10.1016/j.actbio.2017.01.036

Yazici, Y., McAlindon, T. E., Gibofsky, A., Lane, N. E., Lattermann, C., Skrepnik, N., et al. (2021). A Phase $2 b$ Randomized Trial of Lorecivivint, a Novel Intraarticular CLK2/DYRK1A Inhibitor and Wnt Pathway Modulator for Knee Osteoarthritis. Osteoarthritis Cartilage 29 (5), 654-666. doi:10.1016/ j.joca.2021.02.004

Zhang, W., Moskowitz, R. W., Nuki, G., Abramson, S., Altman, R. D., Arden, N., et al. (2008). OARSI Recommendations for the Management of Hip and Knee Osteoarthritis, Part II: OARSI Evidence-Based, Expert Consensus Guidelines. Osteoarthritis Cartilage 16 (2), 137-162. doi:10.1016/j.joca.2007.12.013

Zhang, W., Nuki, G., Moskowitz, R. W., Abramson, S., Altman, R. D., Arden, N. K., et al. (2010). OARSI Recommendations for the Management of Hip and Knee Osteoarthritis: Part III: Changes in Evidence Following Systematic Cumulative Update of Research Published through January 2009. Osteoarthritis Cartilage 18 (4), 476-499. doi:10.1016/j.joca.2010.01.013

Zhang, S., Teo, K. Y. W., Chuah, S. J., Lai, R. C., Lim, S. K., and Toh, W. S. (2019). MSC Exosomes Alleviate Temporomandibular Joint Osteoarthritis by Attenuating Inflammation and Restoring Matrix Homeostasis. Biomaterials 200, 35-47. doi:10.1016/j.biomaterials.2019.02.006

Zheng, W., Feng, Z., You, S., Zhang, H., Tao, Z., Wang, Q., et al. (2017). Fisetin Inhibits IL- $1 \beta$-induced Inflammatory Response in Human Osteoarthritis Chondrocytes through Activating SIRT1 and Attenuates the Progression of Osteoarthritis in Mice. Int. Immunopharmacol. 45, 135-147. doi:10.1016/ j.intimp.2017.02.009

Zhu, X., Chan, Y. T., Yung, P. S. H., Tuan, R. S., and Jiang, Y. (2020). Subchondral Bone Remodeling: A Therapeutic Target for Osteoarthritis. Front. Cel. Dev. Biol. 8, 607764. doi:10.3389/fcell.2020.607764

Conflict of Interest: The authors declare that the research was conducted in the absence of any commercial or financial relationships that could be construed as a potential conflict of interest.

Publisher's Note: All claims expressed in this article are solely those of the authors and do not necessarily represent those of their affiliated organizations, or those of the publisher, the editors and the reviewers. Any product that may be evaluated in this article, or claim that may be made by its manufacturer, is not guaranteed or endorsed by the publisher.

Copyright (C) 2021 Chen, Weng, Liu, Aspera-Werz, Nüssler and Xu. This is an openaccess article distributed under the terms of the Creative Commons Attribution License (CC BY). The use, distribution or reproduction in other forums is permitted, provided the original author(s) and the copyright owner(s) are credited and that the original publication in this journal is cited, in accordance with accepted academic practice. No use, distribution or reproduction is permitted which does not comply with these terms. 